\title{
Arbor
}

\section{El fuero de Córdoba: edición crítica y traducción}

\section{Joaquín Mellado Rodríguez}

Arbor CLXVI, 654 (Junio 2000), 191-231 pp.

\section{Introducción*}

No es esta la primera vez que nos ocupamos del Fuero de Córdoba: ya lo hicimos en $1990^{1}$. Entonces centramos nuestra atención en dos aspectos: la edición de los textos, editados con anterioridad en varias ocasiones, pero con poca fortuna, pues hasta ese momento la edición más aceptable seguía siendo la de Victoriano Rivera, del siglo pasado ${ }^{2}$, a pesar de la reciente de Julio González ${ }^{3}$; pero también realizamos un estudio de las fuentes y de la primera rúbrica, muy peculiar por su extraordinaria extensión y su redacción, a veces, auténticamente farragosa. En el estudio de las fuentes seguíamos muy de cerca el realizado por García-Gallo ${ }^{4}$ para la parte tomada del fuero de Toledo ${ }^{5}$, y pudimos comprobar cómo el resto (las rúbricas comprendidas en la redacción romance) presenta un parentesco significativo con fueros extremeños, sin ignorar otras similitudes de la materia jurídica con la de fueros muy diversos y distantes en el tiempo y en el espacio, como leoneses, los de Úbeda, Cuenca, Baeza, Andújar, Sepúlveda y Guadalajara entre otros.

Hoy abordamos otro aspecto, la edición crítica, que acompañamos también de la traducción. Con ella saldamos un compromiso personal y salimos al paso de diversas conjeturas sobre el grado de fidelidad del texto cordobés para con sus modelos; pero, al mismo tiempo, ofrecemos a la comunidad científica otros muchos datos de interés no sólo 
para el medievalista o historiador del derecho, sino también para el filólogo.

Como ya es sabido, del Fuero de Córdoba se conservan dos versiones: una en romance y otra en latín. La primera, de dudosa validez legal -al carecer de requisitos cancillerescos elementales como son las cláusulas finales de concesión, confirmación y ratificación, la de conminación y penas para los que violen la carta y, especialmente, la suscripción real y relación de confirmantes-, está datada en Córdoba el 3 de marzo de 1241. Parece que el rey mandó redactar apresuradamente un texto foral, a petición de los propios cordobeses, según se desprende del análisis interno del texto ${ }^{6}$; esta es también la autorizada opinión de J. González: «en realidad», afirma, «se debió redactar a gusto de los cordobeses un fuero privativo no muy extenso» ... «Indudablemente se preparó con cierta premura, como resultado de súplica, y sin tener a mano un ejemplar del Liber Iudicum ni del fuero de Toledo» ${ }^{7}$. Su protocolo, escrito en latín, termina anunciando que la parte dispositiva se redactará in uulgari ydiomate para facilitar su comprensión, volviendo al latín sólo para la data final con la que concluye el documento ${ }^{8}$. En la rúbrica 4 de dicho texto el rey concedía a los caballeros de Córdoba todas las franquicias y privilegios de que gozaban los caballeros de Toledo, con algunas salvedades. Pues bien, una vez redactado el fuero, y por razones que desconocemos, el rey cambió de opinión y partió para Toledo dejando el documento truncado, sin la firma real ni relación de confirmantes ${ }^{9}$.

Pero no echa en olvido lo prometido a los cordobeses y el 8 de abril, sólo 36 días después, firma en Toledo el texto definitivo del fuero, todo él en latín, con nuevo protocolo y adornado también de escatocolo con todos los requisitos cancillerescos, incluido sello de plata de que estuvo provisto, según el testimonio de múltiples testigos, hasta casi mediados del siglo XX ${ }^{10}$. En nuestra edición (1990: 42-52), dejando de lado el protocolo (que, aunque toma fragmentos completos del de la confirmación de Fernando III de 1222 , está adaptado al momento histórico y con alusiones a circunstancias concretas de la conquista de Córdoba), distribuimos la parte dispositiva del texto en 58 rúbricas cuyo origen hay que dividir en dos grandes apartados:

a) Texto procedente de la redacción romance: comprende 22 rúbricas (las 1-3 y 40-58), que son una traducción, unas veces escrupulosa y otras no tanto, de esa fuente ${ }^{11}$. En ocasiones, las variantes están más 
El fuero de Córdoba: edición crítica y traducción

que justificadas para subsanar las ambigüedades e incluso contradicciones de la deficiente redacción romance (cf. especialmente $1.10 \mathrm{y}$ 1.11); pero en otras, se introducen recortes aún no explicados suficientemente $^{12}$.

b) Texto procedente de los fueros de Toledo: en lugar de traducir la rúbrica 4 del romance, ya mencionada, transcribe literalmente, salvo ciertas licencias ${ }^{13}$, todas las franquicias y privilegios en ella aludidos. Comprende 36 rúbricas (4-39) ${ }^{14}$, tomadas de la confirmación otorgada por Fernando III, en 1222, a los caballeros de Toledo ${ }^{15}$. Este documento es una refundición de varios privilegios reales anteriores:

- las rúbricas 4-33 comprenden exclusivamente el fuero llamado «de los mozárabes» (no completo) concedido por Alfonso VII a los mozárabes de Toledo, supuestamente en 1118 pero que, según demostramos (1990: 13, n. 15), apoyándonos en A. García-Gallo, es de $1156{ }^{16}$;

- la 34 está tomada de la parte dispositiva del privilegio de Alfonso VIII de 30-9-1182 ${ }^{17}$;

- la 35, del privilegio de Alfonso VIII de 24-9-1202 ${ }^{18}$;

- la 36 se toma de la rúbrica primera del privilegio de Alfonso VIII del 22-2-1207 ${ }^{19}$;

- la 37, de la rúbrica tercera del mismo privilegio;

- la 38, de la rúbrica primera del privilegio de Alfonso VIII de 3-2-1207 ${ }^{20}$;

- la 39, de la rúbrica cuarta del privilegio anterior.

Tenemos la enorme fortuna de contar con los pergaminos originales de las dos versiones, lo que supone una gran ventaja para su estudio histórico y filológico, pues han llegado a nuestras manos exactamente como salieron de la cancillería real ${ }^{21}$. Ahora bien, como el fuero de Córdoba, el único fuero auténtico, es el del texto latino -que denominaremos $L-$, hemos de plantear su estudio crítico desde dos perspectivas muy diferentes:

1. ${ }^{a}$ Estudio de las rúbricas 1-3 y 40-58 de nuestra edición, es decir, la parte traducida al latín desde la redacción originaria en romance. Como desconocemos el verdadero origen de estos preceptos, sólo podemos cotejar el texto latino con el romance que le sirvió de modelo, la redacción datada el 3 de Marzo de 1241, que denominaremos $R$ (romance). Señalaremos como variante toda traducción latina que no se corresponda literalmente con el texto base, aun 
consciente del riesgo de subjetividad que ello comporta. De esta forma, podremos valorar no sólo los aspectos relevantes para el historiador, sino también para el filólogo ${ }^{22}$.

2. ${ }^{\text {a }}$ Estudio del texto importado de los fueros de Toledo (rúbricas 4-39): procede, pues, cotejar el original de nuestro texto con el códice toledano que le sirvió de modelo, el de la confirmación otorgada por Fernando III el 16 de enero de 1222. Ello nos permitirá verificar el grado de fidelidad del texto cordobés, aun consciente de las obligadas variantes exigidas por las diferencias gramaticales entre un texto redactado en tercera persona (la parte dispositiva de la confirmación toledana), y otro en primera (el fuero de Córdoba), y la diferencia de concejo destinatario (Toledo / Córdoba) y sus moradores respectivos. Pero aquí comienzan nuestras dificultades, pues no se ha conservado el original de dicho documento, por lo que nos vemos obligados a recurrir a una copia. Para encontrarla tenemos que remontarnos al año 1254, en que Alfonso X confirma a los habitantes de Toledo precisamente estos mismos fueros, sobrecartándolos en un documento que firma el 2 de $\mathrm{Marzo}^{23}$, es decir, trece años después de nuestro texto. Nadie pone en duda que este documento alfonsino se copiara directamente del original depositado en la propia cancillería real; pero ante una lectura discordante con nuestro $L$, no podremos saber cuál de ellos sigue la lectura del modelo común a ambos -la confirmación fernandina de 1222- y cuál no, si no contamos con otros testigos. Ahora bien, no conocemos más copias directas de dicho documento, por lo que hemos de buscar esos testigos no entre los textos posteriores, sino entre los precedentes: ya hemos visto que la confirmación fernandina es una refundición de varios textos anteriores; pues bien, acudiremos a los originales de esos textos confirmados por Fernando III.

El cuerpo fundamental está constituido, como hemos visto, por el llamado fuero de los mozárabes (rúbricas 4-33), de 1156. Se ha perdido el original, pero conservamos varias copias:

- La más antigua es de $1179^{24}$, denominada por García-Gallo $T^{25}$ que es también la más conocida por haber servido de base a la edición de Muñoz ${ }^{26}$.

- Pero de este documento se hizo otra copia, hoy perdida, que habría servido de modelo, según deduce García-Gallo en virtud de ciertas concomitancias textuales ${ }^{27}$, para dos confirmaciones posteriores de este fuero: 
El fuero de Córdoba: edición crítica y traducción

a) la hecha por Alfonso VIII el 15 de Febrero de 1174, cuyo original también se ha perdido y de la que se conserva una copia, asimismo antigua, que García-Gallo identifica como $A^{28}$.

b) la de Fernando III de 1222 -original perdido- de donde, como hemos afirmado supra, se copian nuestro $L$ y la confirmación de Alfonso $\mathrm{X}$ de 2-3-1254 (el documento original que García-Gallo consideraba copia) y que este autor denomina $F$.

Pero, como podrá constatarse en el aparato crítico, a pesar de las observaciones de García-Gallo (cf. nuestra nota 27), el gran volumen y la identidad de las concomitancias entre $F$ y $T$, según tendremos ocasión de comentar con más detalle en nuestras conclusiones, son suficiente argumento para afirmar que $F$ se encuentra mucho más próximo a $T$ que a $A$.

Las seis rúbricas toledanas restantes (34-39) no están incluidas en $T$ ni en $A$, por lo que, para aportar otro testimonio además de $F$, y ya que se conservan los documentos originales, recurrimos también a ellos, según la edición de J. González ${ }^{29}$.

Antes de concluir, debemos hacer unas observaciones:

a) Algo más de la primera mitad de la línea 13 de $L$ se encuentra gravemente dañada por un doblez del pergamino. Hemos reconstruido el texto por la copia existente en el Archivo de la Catedral de Córdoba, de h. $1318^{30}$.

b) Hemos señalado en el texto con negrita, para facilitar su identificación, la primera letra de las palabras de las que aparecen variantes en el aparato crítico.

c) Recordamos, de manera resumida, la explicación de las siglas del aparato crítico: $L$ versión original latina y definitiva del Fuero de Córdoba que sirve de base a nuestro texto; $R$ primera redacción, en romance, del Fuero de Córdoba; $T$ Copia de 1179 de la recopilación de los Fueros de Toledo otorgados por Alfonso VII en 1156 (datados por error en 1118); $A$ copia de la Confirmación de Alfonso VIII (152-1174); $F$ original fechado el 2 de Marzo de 1254 de la Confirmación otorgada por Alfonso X, que sobrecarta la Confirmación de Fernando III de 16 de enero de 1222 (original perdido); or. documento original respectivo, según la edición de Julio González. 


\section{Edición}

\section{CHRISTVS, Alfa Omega}

Ut facta regum et principum memoriam qua digna sunt assequantur, scripture sunt beneficio solidanda. Iccirco ego, Ferrandus, Dej gratia rex Castelle et Toleti et Legionis et Gallecie et Cordube, sub imperio alme et indiuidue Trinitatis, Patris uidelicet et Filij et Spiritus Sancti, unius quidem omnipotentis Dej, ad honorem beatissime Dej genitricis semperque uirginis Marie, et beatorum apostolorum $\left.\right|^{2}$ Petri et Paulj, in quorum festiuitate ciuitas Corduba reddita fuit cultuj christiano, ex assensu et beneplacito regine domine Berengarie, karissime genitricjs mee, una cum uxore mea, regina Iohanna, et cum filiis meis, Alfonso, Frederico, Ferrando et Henrico, dono et concedo cartam forj populo Cordubensi, presentibus et futuris, omnj tempore ualituram.

1 Dono igitur $\left.\right|^{3}$ et concedo pro foro populo Cordubensi quod iudex et alcaldes et maiordom $u s$ et scriptor mutentur annuatim.

$2 E t$ alcaldes sint quatuor.

3 Et collatio cuj euenerit electio, tota illa collatio eligat quatuor bonos uiros qui sint apti ad istos portellos.

$4 E t$ isti quatuor de predicta collatione iaciant sortem quis eorum sit in portello. Et ille super quem sors ceciderit, sit in portello usque $\left.\right|^{4}$ ad unum annum.

5 Et posuerunt annum de Sancto Iohanne usque ad Sanctum Iohannem.

6 Et si omnes de predicta collatione in unum non concordauerint in electione istorum quatuor, accipiat predicta collatio tota singulos

1.1. pro foro populo Cordubensi] $R$ omite. 1.3. illa] $R$ la. 1.4. predicta] $R$ la; quis eorum sit] $R$ qual caya. 1.6. omnes de predicta] $R$ los de la; predictal $R$ la; ciuitatis] $R$ omite; boni] $R$ omite; Dei] $R$ omite; illi quos eligere debent] $R$ omite; tales] $R$ omes; illorum] $R$ omite; sit aportellatus] $R$ sealo. 1.7. omnes] $R$ omite. 1.8. illi] $R$ los; illos] $R$ los; bonos] $R$ omite; bonos] $R$ omite. 1.9. electio] $R$ escogencia. 1.10. quis sit iudex et quis maiordomus et quis scribanus et quis alcaldus] $R$ a qual collacion caera iuez et a qual mayordomo et a qual escriuano et a qual alcalde; sors] $R$ omite. 1.11. ille super quem sors ceciderit quod sit scriptor nesciuerit scribere, ponat alium loco sui] $R$ la collacion a qui cayere por suerte escriuano non houiere hi esciuano, que aquel omme bueno, a qui cayere la suerte, meta hi tal escriuano; ad istud officium] $R$ por al lugar, si el por si escreuir non sopiere; ille scriptor] $R$ el escriuano; loco sui] $R$ hi. 1.12. ipsemet compleat per se ipsum] $R$ el por si lo cumpla; alium] $R$ añade en su lugar; ipse compleat per se ipsum] $R$ el por si lo cumpla. 1.13. illa collatio de qua] $R$ la collacion don. 


\section{El fuero de Córdoba: edición crítica y traducción}

\section{(Crismón)}

Para que las acciones de reyes y príncipes alcancen la memoria de que son dignas, deben consolidarse con el beneficio de la escritura. Por eso yo, Fernando, por la gracia de Dios rey de Castilla, Toledo, León, Galicia y Córdoba, bajo los designios de la santa e indivisible Trinidad, esto es, Padre, Hijo y Espíritu Santo, un solo Dios omnipotente, y en honor de la santísima Madre de Dios y siempre Virgen María, y los santos apóstoles Pedro y Pablo, en cuya festividad la ciudad de Córdoba fue restituida al culto cristiano; con el consentimiento y beneplácito de la reina Doña Berenguela, mi queridísima madre, junto con mi esposa, la reina Juana, y con mis hijos Alfonso, Fadrique, Fernando y Enrique, otorgo y concedo al concejo de Córdoba presente y futuro carta de fuero válida para siempre.

Otorgo, pues, y concedo por fuero al concejo de Córdoba que renueve anualmente el juez, los alcaldes, el mayordomo y el escribano.

$2 \mathrm{Y}$ que los alcaldes sean cuatro.

3 Y la collación a la que correspondiere la elección, elija toda ella cuatro hombres buenos que sean aptos para estos cargos.

$4 \mathrm{Y}$ estos cuatro de la antedicha collación echen a suerte cuál de ellos estará en el cargo. Y aquel sobre quien recayere la suerte, permanezca en el cargo hasta un año.

$5 \mathrm{Y}$ establecieron el año de san Juan a san Juan.

$6 \mathrm{Y}$ si todos los de la collación antedicha no llegaran a un acuerdo en la elección de estos cuatro, tome dicha collación entera sendos 
bonos uiros de omnibus aliis collationibus ciuitatis. Et isti bonj uiri iurent super sacrosancta Dej Euangelia quod eligant quatuor bonos uiros de illa collatione que non se acordat. Et illi quos eligere $\left.\right|^{5}$ debent, sint tales qui conueniant ad istos portellos. Et isti quatuor iaciant sortem quis illorum sit portellatus; et super quem ceciderit sors, sit aportellatus.

7 Et qui uno anno fuit aportellatus, non sit usquequo compleantur omnes alie collationes.

8 Et si forte illj de collatione qui non concordauerint in eligendo istos quatuor, non concordauerint in eligendo illos bonos uiros de collationibus qui debent eligere $\left.\right|^{6}$ istos quatuor, mittant ad regem suos bonos homines et quomodo ipse mandauerit ita sit.

9 Et hec electio debet esse antequam annus compleatur, a die Ascensionis usque ad Sanctum Iohannem.

10 Et iste collationes que debent iacere sortem, iaciant sortem quis sit iudex et quis maiordomus et quis scribanus et quis alcaldus. Et super quemcumque ceciderit sors, sit de illis quatuor.

11 Et si forte ille super quem $\left.\right|^{7}$ sors ceciderit quod sit scriptor nesciuerit scribere, ponat alium loco sui qui sit conueniens ad istud officium. Et si aliquem deffectum fecerit ille scriptor, paret se ad penam qui eum posuerit loco sui.

12 Et super quemcumque ceciderit sors alcaldie uel iudgatus uel maiordomatus, non ponat alium loco suj, set ipsemet compleat per se ipsum. Et si scriptor sciuerit scribere, non ponat alium $\left.\right|^{8}$ set, sicut supradictum est, ipse compleat per se ipsum.

13 Et si forte iudex uel scribanus uel alcaldus uel maiordomus mortuus fuerit ante annum, illa collatio de qua fuerit eligat alium qui sit loco ipsius, ordinamento superius memorato.

2 Mando etiam et concedo pro foro quod quicumque de alia lege fuit, uel suspectus fuerit de heresi, uel exiuit de ordine, uel fuerit publice excomunicatus, nunquam sit in aliquo portello.

3 Concedo etiam et $\mid{ }^{9}$ mando concilio Cordubensi quod habeant pro ad suum iudicem et pro ad suos alcaldes et pro ad suum maiordomum et pro ad suum scribanum almotacenatgum cum totis suis directuris, et tendam del azeyet, et unam caballeriam de unaquaque caualcata, et suam partem de calumpniis sicut habent uille que habent iudicem et alcaldes.

2. nunquam] $R$ non.

3. mando] $R$ do; sicut habent uille que] $R$ como las an en las uillas o. 
hombres buenos de todas las restantes collaciones de la ciudad. $\mathrm{Y}$ estos hombres buenos juren sobre los santos Evangelios de Dios que elegirán cuatro hombres buenos de aquella collación que no llegó a un acuerdo. Y aquellos a los que han de elegir sean idóneos para estos cargos. Y estos cuatro echen a suerte cuál de ellos ocupará el cargo; y sobre el que recayere la suerte sea el aportillado. $7 \mathrm{Y}$ el que un año fue aportillado, no vuelva a serlo hasta que todas las demás collaciones hayan ejercido su turno.

$8 \mathrm{Y}$ si, por azar, los de la collación que no llegaron a un acuerdo al elegir a estos cuatro, tampoco coincidieran en la elección de los buenos hombres de las otras collaciones, encargados de elegir a estos cuatro, envíen sus hombres buenos ante el rey y que se haga como él mandare.

9 Y esta elección debe realizarse antes de que se cumpla el año, entre el día de la Ascensión y el de san Juan.

$10 \mathrm{Y}$ estas collaciones que han de echar suerte, deberán sortear quién será juez, quién mayordomo, quién escribano y quién alcalde. Y sobre el que recayere la suerte, sea de aquellos cuatro.

$11 \mathrm{Y}$ si, por azar, aquel a quien correspondiere ser escribano no supiera escribir, ponga a otro en su lugar, idóneo para tal oficio. $\mathrm{Y}$ si el sustituto cometiera alguna falta, aténgase a la sanción quien lo puso en su lugar.

$12 \mathrm{Y}$ a quien cayere la suerte de la alcaldía, juzgado o mayordomía, no ponga a otro en su lugar, sino que ejerza él mismo personalmente. $\mathrm{Y}$ si el escribano supiere escribir, no delegue en otro sino que, como se ha dicho antes, ejerza él personalmente.

$13 \mathrm{Y}$ si acaso el juez, escribano, alcalde o mayordomo falleciere antes del año, elija su collación otro en su lugar con arreglo al procedimiento anteriormente establecido.

Mando también y concedo por fuero que todo aquel procedente de otra religión, o sobre el que haya recaído sospecha de herejía, así como el salido de orden religiosa y quien haya sido excomulgado públicamente, jamás ocupe uno de estos cargos.

Otorgo también y mando al concejo de Córdoba que establezcan para su juez, sus alcaldes, su mayordomo y su escribano el almotacenazgo con todos sus derechos, tienda de aceite, una caballería de cada cabalgada y su parte correspondiente de las multas, como tienen las villas que disponen de juez y alcaldes. 
4 Concedo itaque uobis ut omnia iudicia uestra secundum Librum Iudicum sint iudicata coram decem ex nobilissimis illorum et sapientissimis qui fuerint inter $\left.\right|^{10}$ uos, qui sedeant semper cum alcaldibus ciuitatis ad examinanda judicia populorum, et ut precedant omnes in testimonijs in uniuersa terra dominationis mee.

5 Similiter et omnes clericj, qui nocte et die pro me et pro uobis et pro omnibus christianis omnipotentem Deum exorant, habeant absolutas suas hereditates in redendis decimis.

6 Et si quis captiuus christianus exjerit in captiuo mauro, non det portaticum.

7 Et quantum ego dedj uel dedero militibus Cordubensibus de muneribus suis et pro- $\left.\right|^{11}$ ficuis, sit diuisum inter illos quomodo fuerint in numero uni ab alijs.

8 Et mando quod non sint pignoratj, tam milites quam ceteri ciues Cordubenses, in uniuerso regno meo. Quod si aliquis ausus fuerit unum ex illis in omnibus regionibus meis pignorare, duplet pignora illa et soluat regi sexaginta aureos.

9 Adhuc autem et milites illorum non faciant anubdam, nisi unum fonsatum in anno. Et qui remanserit ab illo fonsato sine ueredica excusatio- $1^{12}$ ne, soluat regi decem solidos.

10 Et qui ex illis obierit et equum aut loricam seu aliqua arma regis tenuerit, hereditent omnia filij suj siue sui propinqui et remaneant

4. Concedo itaque uobis ut] $T A F$ Sic uero et; uestra] $T A F$ eorum; qui fuerint inter uos] $T A F$ illorum; alcaldibus] $T A F$ iudice; populorum] $A$ añade exceptis Castellanorum. Omnis tamen Castellanus qui ad suum forum ire uoluerit, uadat; testimoniis] $T A$ testimonium; uniuersa terra dominationis mee] $T A F$ uniuerso regno illius.

5. absolutas suas hereditates] $T A$ omnes suas hereditates liberas; redendis] $T$ $A F$ reddendis; decimis] $T A F$ añaden Sic uero dedit libertatem militibus a portatico de caballis et mulis in ciuitate Toleto.

6. captiuus] $L$ captiuuus.

7. ego dedi uel dedero militibus Cordubensibus] $T$ A $F$ dederit rex militibus Toleti; suis et] $T A F$ siue; illos] $T A F$ añaden scilicet Castellanos et Gallecos ( $F$ Gallegos) et Muzarabes.

8. mando] $T A F$ omiten; Cordubenses] $T A$ Toleti, $F$ Toletani; regno] $A$ regio; meo] $T A F$ illius; aliquis ausus fuerit unum ex illis] $T$ ausus fuerit unum ex illis aliquis; omnibus regionibus] $A$ omni regione; meis] $T F$ suis, $A$ sua; aureos] $T A F$ solidos.

9. anubdam] $T$ annudbam, $A F$ annubdam; unum fonsatuml $T A F$ uno fossato; fonsatol $T A F$ fossato; ueridical $A$ uera.

10. aliqua armal $T F$ aliquas armas; omnia] $A$ ea; siue sui propinqui] $A$ siue propinqui sui, $T$ repite siue sui; illorum] $A$ sui. 10.2. relinquerit] $A$ dimiserit; in] $A$ omite. 
Así pues ${ }^{1}$, os concedo que todos vuestros juicios se tramiten, conforme al Fuero Juzgo, ante diez de los más nobles y sabios de entre vosotros, los cuales se sentarán siempre con los alcaldes de la ciudad para examinar los juicios de los pueblos y habrán de preceder a todos en sus declaraciones en todas las tierras de mi señorío ${ }^{2}$.

Y de igual manera, que todos los clérigos, que noche y día ruegan a Dios todopoderoso por mí, por vosotros y por todos los cristianos, tengan sus heredades exentas del pago del diezmo.

Y si algún cautivo cristiano fuera canjeado por un cautivo moro, 6 que no pague portazgo.

Y cuanto yo he dado o diere a los caballeros de Córdoba de donadíos y provechos, sea dividido entre ellos en partes proporcionales al número.

Y mando que no sean embargados los caballeros ni los demás ciudadanos cordobeses en todo mi reino. Y si alguien osare embargar a uno de ellos en todos mis dominios, duplique lo embargado y pague al rey sesenta sueldos de oro.

Más aún, y que sus caballeros no hagan anubda ${ }^{3}$, sino un solo fonsado ${ }^{4}$ al año. $\mathrm{Y}$ el que no acudiere al fonsado sin verdadera excusa, pague al rey diez sueldos.

$\mathrm{Y}$ si alguno de ellos muriere teniendo caballo, loriga $\mathrm{u}$ otras armas del rey, hereden todo esto sus hijos o parientes y permanezcan

1 Aquí comienza la relación de «franquezas y privilegios que han los caualleros de Toledo" aludidos en la rúbrica 4 del texto romance y que hemos identificado en la introducción. Concretamente, las rúbricas 4-33 pertenecen al llamado «Fuero de los Mozárabes", otorgado por Alfonso VII a los toledanos en 1156.

2 En éste como en otros casos, adapto la terminología a la traducción literal que se hizo del fuero cordobés y que otorgó Alfonso X como fuero a Écija, el 12 de abril de 1266. El original de este fuero se perdió, pero quedó en Écija una copia en el Tumbo de los Reyes Católicos. Citamos por la edición de $\mathrm{M}^{\mathrm{a}}$ Josefa Sanz, o. c.

3 Término árabe generalizado en romance en época medieval. Consistía ésta en una prestación personal para reparar los muros, torres y fortificaciones, o para ejercer servicio de vigilancia y protección durante la realización de estos trabajos. En algunos textos designa también el impuesto que, previo pago, eximía de esta obligación.

$4 \mathrm{El}$ fonsado era una expedición de guerra a la que tenían que acudir todos los moradores no dispensados por fuero. 
cum matre sua honoratj et liberi in honore patris illorum, donec ualeant equitare.

2 Nam et si solam uxorem relinquerit, sit honorata in honore maritj suj.

11 Sic quoque et qui intus ciuitatis aut foras in uillis, in solaribus suis, comorauerint, et contentiones et iurgia inter $\mid{ }^{13}$ [illos ceciderint, omnes calumpnie suorum sint ipsorum.

12 Si quis uero ex illis in Castellam seu in Galleciam aut in terram Legionis seu quamcumque terram ire uoluerit, relinquat caballarium in domo sua qui pro eo seruiat infra tantum et uadat cum Dei benedictione.

13 Et quicumque cum uxore sua ad suas hereditates ultra portum ire uoluerit], relinquat caballarium in domo sua et uadat in octubro et ueniat in primo madio. Quod si ad hoc tempus non uenerit $\mathrm{I}^{14}$ et ueridicam excusationem non habuerit, soluat regi sexaginta solidos.

2 Si uero uxorem secum non leuauerit, non relinquat cum ea caballarium; tamen ad hoc placitum ueniat.

14 Et si quis de peditibus equitare potuerit uel uoluerit in aliquibus temporibus, equitet et intret in mores militum.

15 Necnon ipsi et filij suj et heredes eorum habeant omnes hereditates suas fixas et stabilitas usque in perpetuum; et uendant et emant unj ab alteris et donent ad que[m] $\left.\right|^{15}$ quesierint; et unusquisque faciat in sua hereditate secund $u \mathrm{~m}$ suam uoluntatem.

11. aut] $A$ uel; suorum sint ipsorum] $T F$ ipsorum sint suorum, $A$ ipsorum sint eorum.

12. Castellam seu in Galleciam aut in terram Legionis] $T$ Franciam aut in Castellam siue ad Galleciam, $A$ Franciam siue in Galleciam aut in Castellam, $F$ Francia aut in Castella siue ad Galleciam; seu] $A$ añade in; caballarium] $T A F$ caballerum; uadat cum Dei benedictione] $A$ cum Dei benedictione uadat.

13. Et] $F$ Quod; portum] $T A F$ serram; caballarium] $T A$ caballerum, $F$ caballero; octubro] $T A F$ octubrio; madio] $T$ maio, $A$ mayo; tempus] $T A$ terminum, $F$ tamen. 13.2. secum] $T A F$ omiten; leuauerit] $F$ leuaberit; caballarium] $T A$ cauallerum, $F$ cabalerum; ueniat] $A$ inueniatur (sigue una palabra perdida por desgarro del pergamino que afecta verticalmente a diez lineas).

14. si quis de peditibus] $T A F$ quisquis ex illis; potuerit uel] $T A F$ omiten; aliquibus] $T F$ quibusdam.

15. ipsi ... hereditates] $T F$ et habeant ipsi et heredes eorum omnes hereditates, A ip- (perdido por desgarro -si [...]) -lii et heredes eo- (perdido -rum [...] heredita-) -tes; suas] $T$ omite; fixas] $L$ ficxas; et] $T A F$ añaden quod; alteris] $A$ aliis. 


\section{El fuero de Córdoba: edición crítica y traducción}

con su madre honrados y libres de obligaciones, en honor de su padre, hasta que sean capaces de cabalgar.

2 Incluso si dejare a su mujer sola, sea honrada en honor de su marido.

Así también, que recaigan sobre estos caballeros todas las responsabilidades de eventuales altercados o querellas entre quienes moren en sus posesiones, sea dentro de la ciudad o fuera en las villas.

Y si alguno de ellos quisiere ir a Castilla o a Galicia o a tierras de León o a cualquiera otra parte, deje un escudero ${ }^{5}$ en su casa que sirva por él entre tanto y vaya con la bendición de Dios. $\mathrm{Y}$ quien quisiere ir con su mujer a sus heredades allende el puerto ${ }^{6}$, deje un escudero ${ }^{7}$ en su casa y que se vaya en octubre $\mathrm{y}$ vuelva a primeros de mayo. $\mathrm{Y}$ si no volviere para esta fecha sin verdadera justificación, pague al rey sesenta sueldos.

2 Pero si no llevare consigo a su mujer, no deje escudero con ella, aunque deberá regresar en este plazo.

$\mathrm{Y}$ si alguno de los peones pudiere y quisiere cabalgar en alguna 14 ocasión, cabalgue y acceda a las costumbres de los caballeros.

$\mathrm{Y}$ tanto ellos mismos como sus hijos y herederos tengan sus he- $\mathbf{1 5}$ redades fijas y consolidadas a perpetuidad, de forma que puedan vender y comprar unos de otros y donar a quien quisieren; y cada uno haga en su heredad según su voluntad.

5 También aquí seguimos la traducción hecha para el fuero de Écija.

6 Nos encontramos ante uno de los problemas más arduos, la identificación de este puerto, ya problemático desde el excelente trabajo de Félix Hernández en que identifica al menos seis puertos por los que debía pasar el camino de Córdoba a Toledo (Hernández Jiménenez, F., 1959, «El camino de Córdoba a Toledo», Al-Andalus 24 , pp. 1-66. Al no especificarse el nombre propio, debe tratarse de un punto muy conocido; pues bien, según F. Hernández (o. c. pp. 20 y 37), los dos puertos más destacados en los documentos de Fernando III son el de Alhover, denominado posteriormente de Milagro, en los Montes de Toledo (punto de comunicación entre las cuencas del Tajo y del Guadiana), y puerto Mochuelo, en Sierra Madrona, paso obligado en el camino de Gahete (Belalcázar).

7 Cf. nota 5. 
16 Et si ego abstulero alicuj illorum hereditatem aliquam per iram aut per iniustitiam, absque culpa palatina, quod in eadem, uirtute huius priuilegij, sit reuersus.

17 Item, qui hereditates in quacumque terra regnorum meorum et mee dominationis habuerit, iubeo ut saiones non intrent in eas nec maiorinj, set sint captate et emperate. Istud facio propter amorem popul[atio]- $\left.\right|^{16}$ nis Cordubensium.

18 Item si, quod absit, recuperarent sarracenj aliquam uillam uel ciuitatem aut castrum in quibus hereditates aliquas habuerunt milites Cordubenses et ciues, cum postea dominus reddiderit cultuj christiano huiusmodj uillam uel ciuitatem uel castrum, predictj milites Cordubenses et ciues et heredes eorum recuperent hereditates suas et uendicent eas de Corduba cum moratoribus Cordube.

19 Sic quoque et illj qui ultra $\mid{ }^{17}$ portum sunt, si aliquod iudicium habuerint cum aliquo Cordubensi, quod ueniant ad medianetum ad Ferrat a Toleto et supra, et ad Gafet a Toleto et infra, et ibj se iudicent cum eo.

20 Item, ut Sanctorum Patru $<\mathrm{m}>$ precepta impleantur, quibus obedire uolumus et debemus, iubeo ut nullus iudeus uel nuper renatus habeat mandamentum super ullum christianum in Corduba nec in suo termino nisi esset almoxerifus meus.

16. Et si ego abstulero] $T F$ Sic uero et si auus suus (det illi Deus requiem) abstulit, $A$ Si uero auus suus cuicumque ueniam donet au- (siguen al menos ésta $y$ otra palabra perdida); alicui illorum hereditatem aliquam] $T F$ aliquam hereditatem uni eorum, $A$ (perdida al menos una palabra) eorum suam hereditatem; iniustitiam] $T A F$ iniusticiam; eadem, uirtute huius priuilegii] $T A F$ ea.

17. Item] $T A F$ Et item; meorum] $T A F$ illius; et mee dominationis] $T A F$ omiten; iubeo] $T A F$ iussit; nec] $T A$ neque; maiorini] $T$ merinos, $A F$ maiorinos; captate et emperate] $T$ anparate, $A$ imperata, $F$ imperate; istud facio] $T A F$ omiten; propter] $T F$ per; populationis Cordubensium] $T A F$ populationis ( $F$-cio-) illius in Toleto.

18. Item ... hereditates suas et] presenta una redacción muy diferente, aunque temáticamente relacionada con la de las fuentes; Cordubenses] $L$ Cordubensens; uendicent] $A$ uindicent; Corduba] $T$ A F Toleto; Cordube] $T A F$ Toleti.

19. Sic quoque et illi] $A$ Si quid et ipsi; portum] $T A F$ serram; aliquod] $A$ omite; aliquo] A omite; Cordubensi] T A F Toletano; quod ueniant] $A$ conueniant; medianetum] $T$ medianedum; ad Ferrat a Toleto et supra, et ad Gafet a Toleto et infra] $T F$ in Calatalifa, $A$ Calatalifa; se iudicent cum eo] $A$ discernatur eis.

20. Item ut Sanctorum Patrum ( $L$ Patruum) precepta impleantur] $T$ Et per Sanctorum Patrum obedire et implere precepta, $A$ Et pro Dei et sanctorum preceptorum hobedientya; quibus obedire uolumus et debemus] $T A F$ omiten; iubeo] $T A F$ iussit (amplificet Deus regnum ipsius $-A$ illius-); uel] $T A F$ nullus; Corduba] $T A F$ Toleto; nec] $T$ neque, $A$ aut; suo termino] $T F$ suo territorio, $A$ circuitu eius; nisi esset almoxerifus meus] $T A F$ omiten. 


\section{El fuero de Córdoba: edición crítica y traducción}

$\mathrm{Y}$ si yo quitare a alguno de ellos una heredad por ira o injusticia, 16 sin culpa manifiesta, sea reintegrado en la misma en virtud de este privilegio.

Asimismo, ordeno que no entren sayones ${ }^{8}$ ni merinos ${ }^{9}$ en las he- 17 redades que éstos posean en cualquier parte de mis reinos y dominios, sino que permanezcan acotadas y amparadas. Hago esto por amor a la población cordobesa.

También si, lo que Dios no quiera, los sarracenos recuperasen alguna villa, ciudad o castillo, donde los caballeros y ciudadanos de Córdoba tuvieran algunas posesiones, una vez que el Señor haya restituido al culto cristiano la mencionada villa, ciudad o castillo, dichos caballeros y ciudadanos de Córdoba y sus herederos recobren sus posesiones y reivindíquenlas como de Córdoba junto con los moradores cordobeses.

Así también, si alguno de allende el puerto ${ }^{10}$ tuviere pleito con un cordobés, venga de medianedo ${ }^{11}$ a Ferrat ${ }^{12}$ desde Toledo hacia el norte, y a Gahete ${ }^{13}$ desde Toledo hacia el sur, y allí litigue con él.

Además, para dar cumplimiento a los preceptos de los Santos Padres, a los que queremos y debemos obedecer, ordeno que ningún judío ni cristiano nuevo tenga autoridad sobre un cristiano en Córdoba ni en su término, a no ser mi almojarife ${ }^{14}$.

8 Oficial subalterno que auxiliaba a jueces y merinos. Era, sobre todo, un oficial inferior de la administración de justicia y un agente ejecutivo: cita a juicio a los litigantes, prende a los malhechores y ejecuta las penas corporales etc. (Para este y otros oficios cf. García de Valdeavellano, L., $1986^{2}$, Curso de Historia de las Instituciones Españolas, Madrid).

9 Oficial público que administraba los grandes dominios territoriales y supervisaba la recaudación de los tributos. Interviene también en asuntos de carácter militar, como responsable de la movilización de los individuos de su circunscripción que debieran ir a la guerra.

10 Cf. nota n. 6.

11 Punto establecido para promediar distancia en los desplazamientos, al que deben concurrir las partes litigantes.

12 Obviamente debe encontrarse más al $\mathrm{N}$ de Gahete, pero resulta difícil su identificación; tal vez se refiera a la actual Herrera del Duque, al NE de la provincia de Badajoz, por donde podría pasar el camino de Córdoba a Toledo.

13 Actual Belalcázar (Córdoba)

14 Oficial real encargado de recaudar las rentas y derechos del rey. 
21 De cetero uero, si $\left.\right|^{18}$ aliquis homo ceciderit in homicidium aut in aliquem liuorem absque sua uolumptate et probatum fuerit per testes ueridicos, si fideiussorem dederit, non sit retrusus in carcerem.

$2 E t$ si fideiussorem non habuerit, non ducatur alicu[b]j extra Cordubam, set tantum in Cordubensi carcere retrudatur et non soluat nisi quintam partem calumpnie et non plus.

22 Qui uero de occisione christiani uel mauri siue iudej per suspicionem acusatus $\left.\right|^{19}$ fuerit, nec fuerint super eum testes ueridicj et fideles, iudicent eum per Librum Iudicum.

23 Si quis uero cum aliquo furto probatus fuerit, totam calumpniam secundum Librum Iudicum soluat.

$24 \mathrm{Si}$ uero, si peccato inpediente, aliquis homo cogitauerit aliquam traditionem in ciuitate aut in castello et discoopertum fuerit per fidelissimas testimonias, ipse solus patiatur malum aut exilium. 2 Si uero fugerit et inuentus non fuerit, portionem suam $\left.\right|^{20}$ de toto suo habere rex recipiat et remaneat uxor sua cum filiis suis in portione sua, intus ciuitatis et foras, sine ullo impedimento.

25 Item statuo et iubeo ut nullus pausatarius pauset in aliqua ex domibus Cordubensium intus ciuitatis nec in uillis suis.

26 Item iubeo et concedo quod nulla ex mulieribus eorum, que uidua fuerit aut uirgo, sit data ad maritum inuitus per aliquam potentem personam.

27 Similiter $\left.\right|^{21}$ et nullus erit ausus rapere mulierem de mulieribus eorum, mala si fuerit aut bona, non in ciuitate nec in uilla nec in uia.

21. testes ueridicos] $T A F$ ueridicas testimonias; carcerem] $T$ carcere; 21.2. ducatur] $A$ feratur; alicubi] $L$ alicuj; Cordubam] $T A F$ Toletum; set] $T F$ sed; Cordubensi] $T$ $A F$ Toletano; retrudatur] $T F$ trudatur, $A$ mittatur, y $T A F$ añaden scilicet de Alfada; et] $T A F$ omiten; non plus] $A$ tantummodo.

22. suspicionem] $T F$ suspitionem; testes ueridici et fideles] $T F$ ueridicas fidelesque testimonias, $A$ ueridicas et fideles testimonias.

23. uero] $A F$ ergo; probatus] $A$ aprehensus.

24. Si] $T A F$ Sic; si] $T A F$ et si; cogitauerit aliquam traditionem ( $T$ tradicionem)] $A$ aliquam traditionem cogitauerit; discoopertum] $T A$ discoopertus; patiatur] $T F$ pateat; 24.2. fugerit] $A$ fuerit; portionem] $T A F$ porcionem; habere] $T A$ auere; rex recipiat] $T F$ regi accipiant, $A$ regi accipiatur; portione] $T A$ porcione; et] $A$ aut; ullo] $A$ aliquo.

25. Item statuo et iubeo] $T A F$ Et iussit; pausatarius] $T F$ pasaterus, $A$ pausator; pauset] $T A F$ descendat; aliqua] $T$ ulla, $A F$ una; Cordubensium] $T A F$ Toletanorum; intus ciuitatis] $A$ in ciuitate; uillis suis] $A$ uilla.

26. Item iubeo et concedo quod nulla ex] $T$ Et, $A$ Et mulier ex, $F$ Quod si mulier ex; que] $T$ si, $A F$ omiten; fuerit] $T A$ sit; aut] $T A F$ an; sit] $T A F$ non sit; ad maritum] $T A$ marito; per] $T$ nec per se neque per, $F$ non per se neque per.

27. de] $T A$ ex; mala si fuerit aut bonal $T$ siue bona siue mala; non] $A$ nec; nec] $A$ aut, $F$ neque; uilla nec in uia] $T F$ uia nec in uilla, $A$ uia neque in uilla; 27.2. 
En adelante, si un hombre cometiere un homicidio u otro delito 21 involuntariamente y se probara esto por medio de testigos veraces, si presentare fiador, no sea encarcelado.

$2 \mathrm{Y}$ si no tuviere fiador, no sea conducido a otro lugar fuera de Córdoba, sino que sea custodiado en la cárcel de la ciudad y pague sólo la quinta parte de la multa, no más.

Quien fuere acusado como sospechoso de la muerte de un cristiano, 22 moro o judío y no hubiere a su favor testigos verídicos y fieles, sea juzgado conforme al Fuero Juzgo.

Aquél de quien se probare que ha hurtado, pague toda la multa 23 conforme al Fuero Juzgo.

Y si, a instancias del pecado, alguno tramare alguna traición en $\mathbf{2 4}$ la ciudad o en un castillo y fuere descubierto por testigos fidelísimos, él solo sufra el daño o el destierro.

2 Pero si huyere y no fuere encontrado, reciba el rey la totalidad de la parte de los bienes correspondientes al fugitivo, y la esposa de éste permanezca con sus hijos en la posesión de su parte, dentro y fuera de la ciudad, sin ningún impedimento.

Asimismo, decreto y ordeno que ningún aposentador ${ }^{15}$ se aposente 25 en casa alguna de cordobeses, ni dentro de la ciudad ni en sus villas.

Ordeno también y otorgo que ninguna de sus mujeres, viuda o 26 doncella, sea dada en matrimonio contra su voluntad por algún poderoso.

Igualmente, que nadie se atreva a violar a ninguna de sus mujeres, 27 deshonesta u honesta, ni en la ciudad, ni en las villas ni caminos.

15 El de posadero o aposentador era un antiguo oficio de la corte regia que cuidaba de todo lo concerniente al hospedaje del rey y de la corte en sus desplazamientos por el reino. Pero durante la baja Edad Media tuvieron también a su cargo cuidar del aposentamiento de los oficiales públicos en los desplazamientos exigidos por el cumplimiento de sus funciones. 
2 Et $\mathbf{q}$ uicumque aliquam ex illis rapuerit, morte moriatur in eodem loco.

28 Iubeo etiam et confirmo ad honorem Christi et christianorum quod, si maurus aliquis uel iudeus cum christiano iudicium habuerit, ad iudicem christianorum ueniat ad iudicium.

29 Item iubeo et concedo quod nullus sit ausus ferre arma aliqua nec caballum aliquem de Cor- $\left.\right|^{22}$ duba ad terras maurorum.

30 Item placet mihi et iubeo statuendo quod ciuitas Corduba nunquam sit prestimonium alicujus nec sit in ea aliquis dominator preter me et successores mej, neque uir neque femina.

31 Item statuo et concedo quod ego semper tempore necessitatis, uita comite et salute, succurram ad defensionem Cordube ut liberem eam ab omnibus uolentibus eam oprimere, siue sint christianj siue mauri.

32 Iubeo insuper statuendo quod nulla $\left.\right|^{23}$ persona habeat hereditatem in Corduba nisi qui moratus fuerit in ea cum filiis suis et uxore sua.

33 Item iubeo et concedo quod fabricatio muri constet semper de comodis et utilitatibus et redditibus regjs.

quicumque aliquam ex illis] $T$ qui unam ex illis, $A$ qui mulierem, $F$ Quod si quis unam ex illis; eodem] $T A F$ omiten.

28. Iubeo etiam ... iudicium habuerit] $T A F$ Sic etiam honorem christianorum confirmauit ut maurus et ( $A$ uel) iudeus si habuerint ( $F$ habuerit) iudicium cum christiano quod.

29. Item iubeo et concedo quod nullus sit ausus ferre] $T A F$ Et quod; arma aliqua nec caballum aliquem] $T A F$ nulla arma neque ullum caballum de sella exeant (A leuent); Corduba] $T A F$ Toleto; maurorum] $A$ sarracenorum.

30. Item placet mihi et iubeo statuendo quod] $T A F$ Et placuit ei ut; Corduba numquam] $T A F$ Toleti non; prestimonium alicuius] $T A$ prestimonio, $F$ prestamo; aliquis dominator] $T F$ dominator, $A$ dominator aliquis; me et successores mei] $T A$ eum solum, $F$ eum.

31. Item ... necessitatis] $T A F$ Et in tempore estatis; uita comite et salute] $T$ $A F$ omiten; succuram ... liberem] $T$ succurrat Toleto et defendat, $A F$ succurrat Toletum deffendere; oprimere] $T A F$ opprimere; sint christiani siue mauri] $A$ christiani siue mauri sint.

32. Iubeo insuper statuendo quod] $T A F$ Et iussit ut; Corduba] $T A F$ Toleto; filiis suis et uxore sua] $A$ uxore et filiis.

33. Item iubeo et concedo quod] $T A F$ Et; muri] $T A F$ muris; comodis] $F$ commodis; et redditibus] $T A F$ omiten; regis] $T F$ Toleti ( $y$ añaden sicut antea erat in tempore 


\section{El fuero de Córdoba: edición crítica y traducción}

$2 \mathrm{Y}$ cualquiera que violare a una de ellas, reciba la muerte en el mismo lugar.

Ordeno también y confirmo, para honra de Cristo y de los cristianos que si un moro o judío litigare con un cristiano, acuda para el juicio al juez de los cristianos.

También mando y concedo que nadie se atreva a pasar armas ni 29 caballo desde Córdoba a tierras de moros.

Pláceme asimismo y ordeno estableciendo que la ciudad de Córdoba $\mathbf{3 0}$ nunca sea préstamo de nadie y que nadie ejerza su dominio sobre ella, ni hombre ni mujer, a excepción de mí y de mis sucesores. También establezco y concedo que, mientras me acompañen la vida $\mathbf{3 1}$ y la salud, acudiré a defender a Córdoba, siempre que lo necesite, para librarla de todos los que quieran oprimirla, ya sean cristianos o moros.

Ordeno además y establezco que ninguna persona tenga heredad 32 en Córdoba, salvo quien morare en ella con sus hijos y esposa. También ordeno y concedo que la reconstrucción de las murallas 33 corra siempre a cargo de los bienes, utilidades y rentas del rey. 
34 Dono insuper et concedo omnibus militibus Cordube et totius terminj sui, presentibus et futuris, quod de omnibus hereditatibus quas habent in Corduba aut in aliqua parte terminj suj, uel de cetero habuerint, nullam decimam $\left.\right|^{24}$ nec forum aliquod regi nec domino terre nec alicuj alij unquam persoluant.

2 Et quicumque hereditates ipsorum de manibus eorum excoluerint, de fructibus inde perceptis nullam decimam tribuant, set predicti milites cum omnibus hereditatibus suis liberi et inmunes ab omnj regalj alioque grauamine et exactione per secula cunta permaneant.

35 Dono insuper et concedo libertatem et absolutionem uobis, toti concilio Cordubensi presentj et futuro, mandans $\left.\right|^{25}$ et firmiter precipiens quod quicumque in Corduba moratj fuerint ibidemque uicinitatem et militiam secundum forum Cordube fecerint, de hereditatibus suis, quas in tota terra mee dominationis habuerint, nullam faciant postam uel facenderam seu pectum aliquod; set pro uicinitate et facendera adque militia Cordube sint excusatj in omnibus aliis uillis totius terre mee dominationis.

36 Iubeo insuper statuendo concilio Cordubensi $\left.\right|^{26}$ quod omnes uille que sunt in termino Cordubensi et aldee, siue sint mee siue de [a]poteca mea, siue dominj episcopi Cordubensis, siue ecclesie Sancte Marie, siue ordinis Calatrauensis, siue hospitalis, siue ordinis de Ucles, siue militis, siue cuiuscumque hominis, facienderam faciant cum ciuitate Cordube sicut faciunt ciues illius ciuitatis.

aui sui regis Ildefonsi $-F$ Aldefonsi regis-), $A$ ciuitatis ( $y$ añade sicut antea fuerat in tempore aui sui Adefonsi senioris, cui perpetua sit beata requies).

34. insuper] or omite; militibus Cordube] $F$ Toleti militibus; totius] $F$ tocius; Corduba] or. $F$ Toleto. 34.2. Et] or. Quod; hereditates ipsorum de manibus eorum] or. $F$ de manibus eorum hereditates ipsorum; excoluerint] or. uoluerint; predicti] or. supradicti.

35. Dono insuper et concedo libertatem et absolutionem] or. $F$ facio cartam libertatis et absolutionis; toti] or. toto; Cordubensi] or. $F$ Toletano; et] or. $F$ ac; Corduba] or. $F$ Toleto; militiam] $F$ miliciam saltin; Cordube] or. $F$ Toleti; tota terra mee dominationis] or. $F$ toto regno meo; adque] or. $F$ atque; militia] or. $F$ milicia; Cordube] or. $F$ Toleti; totius terre mee dominationis] or. $F$ regni mei.

36. Iubeo insuper statuendo] or concedo et confirmo, $F$ Mando et confirmo; Cordubensi] or. $F$ Toletano, sicut fecit proauus meus rex Aldefonsus bone memorie; uille] or. añade et aldee; Cordubensi] or. $F$ Toleti; et aldee] or omite; apoteca] $L$ poteca; episcopi Cordubensi] or. Toletani archiepiscopi, $F$ archiepiscopi Toletani; ordinis Calatrauensis] or. F Salue Terre; siue] or. añade milicie Templi siue; cum] or. in; Cordube] or. $F$ Toleti. 
Doy asimismo y concedo a todos los caballeros de Córdoba y de $\mathbf{3 4}$ todo su término, presentes y futuros, que de todas las heredades que tienen en Córdoba o en cualquier parte de su término, o vayan a tener en el futuro, no paguen jamás diezmo alguno ni foro al rey ni al dueño de la tierra ni a ningún otro.

$2 \mathrm{Y}$ cuantos cultivaren las tierras de éstos por concesión directa de los dueños, no paguen diezmo alguno de los frutos obtenidos de ellas, sino que dichos caballeros con todas sus heredades permanezcan libres y francos a perpetuidad de todo gravamen y exacción real y de cualquier otro tipo.

Doy además y concedo libertad y franquicia a vosotros, todo el $\mathbf{3 5}$ concejo de Córdoba, presente y futuro: mando y firmemente ordeno que quienes habitaren en Córdoba y en ella mantuvieren vecindad y caballería ${ }^{16}$ según el fuero de Córdoba, no realicen posta ${ }^{17} \mathrm{ni}$ facendera ${ }^{18}$ ni pecho ${ }^{19}$ alguno por las heredades que posean en tierras de mi señorío, sino que por la vecindad y facendera y la caballería que mantienen en Córdoba, sean eximidos en todas las otras villas y tierras de mis dominios.

Establezco además y mando al concejo de Córdoba que todas las 36 villas ubicadas en el término de Córdoba, y las aldeas, ya sean de mi propiedad o de mi hipoteca, o del señor obispo de Córdoba, de la iglesia de Santa María ${ }^{20}$, de la orden de Calatrava, del hospital, de la orden de Uclés, o de un caballero o de cualquier otro hombre, hagan facendera con la ciudad de Córdoba como hacen los vecinos de la propia ciudad.

16 He traducido facere militiam siguiendo la interpretación del fuero de Écija, fiel traductor de nuestro texto: "Cualquier que en Cordoua morare e cauallería y mantouiere según el fuero de la villa" (Sanz, o.c., 195).

17 Obligación de actuar de centinela.

18 Trabajos de muy distinto tipo que un vasallo presta a su señor, y especialmente los concernientes a la construcción y reparación de los caminos y puentes del señorío.

19 Tributo, en sentido genérico, aunque también puede designar el pago al señor de alguna renta por el usufructo de la tierra.

20 Como es bien sabido, en los textos forales la iglesia de Santa María se identifica siempre con la iglesia catedral. 
37 Verumtamen de uillis episcopi Cordubensis et aldeis et ecclesie Sancte Marie mandamus ita: $\left.\right|^{27}$ quod postam et feçenderam quam supra diximus illos debere facere cum ciuibus Cordubensibus, faciant eam non per manum eorum, set per manum hominis dominj episcopi qui colligat et det eam alcaldibus Cordube; non enim uolumus quod alcaldes uel ciues Cordubenses habeant aliquam potestatem uel aliquam premiam super homines episcopi et ecclesie Sancte Marie.

2 Et cum ista pecta quam facient ciuibus Cordubensibus, sint liberi et inmunes ab omni $\left.\right|^{28}$ pecta et façendera regis.

$3 \mathrm{Si}$ ego uel filius meus aut aliquis de genere meo uoluerit aliam pectam uel aliam façienderam habere de hominibus supradictis dominj episcopi et ecclesie Sancte Marie, non teneantur aliquam pectam uel façenderam facere cum ciuibus Cordubensibus.

38 Statuo etiam confirmando quod nullus homo de Corduba, siue uir siue mulier, possit dare uel uendere hereditatem suam alicuj ordinj, excepto si uelit $\left.\right|^{29}$ supradictam dare uel uendere Sancte Marie de Corduba quia est sedes ciuitatis. Set de suo mobilj det quantum uoluerit secundum suum forum.

2 Et ordo qui eam acceperit datam uel emptam, amjttat eam.

$3 E t$ qui eam uendiderit amitat morabetinos et habeant eos consanguinej suj propinquiores.

39 Miles autem de alia parte qui hereditatem habet in Corduba uel habuerit, faciat ibi uicinitatem cum suis uicinis; alioquin amit$\mathrm{I}^{30}$ tat eam et conferat eam rex cuicumque uoluerit, $\mathrm{q} u \mathrm{i}$ pro ea faciat uicinitatem.

40 Jubeo etiam et concedo quod pedites uicinj de Corduba et de suo termino nunquam decimam soluant regi.

37. episcopi Cordubensis] or. $F$ domini archiepiscopi; feçenderam] or. $F$ facienderam; Cordubensibus] or. $F$ Toletanis; epicopi] or. $F$ archiepiscopi; Cordube] or. $F$ Toleti; Cordubenses] or. $F$ Toletani; episcopi] or $F$ archiepiscopi. 37.2. Cordubensibus] or. $F$ Toletanis; omni] or. añade alia. 37.3. Si] or. Et si, $F$ Quod si; façienderam] or. facenderam; episcopi] or. $F$ archiepiscopi; aliquam] or añade aliam; Cordubensibus] or. $F$ Toletanis.

38. Statuo etiam confirmando] or. $F$ Statui cum bonis hominibus de Toleto; homo] or. omite; Corduba] or. $F$ Toleto; uelit] or. $F$ uoluerit; supradictam] or. $F$ eam; uel] or. aut; Corduba] or. $F$ Toleto. 38.2. amittat] or.amitat.

39. Corduba] or. $F$ Toleto; alioquin] or alioquim, $F$ allioquin; eam] or. $F$ illam; eam] or. $F$ illam; faciat] or. añade ibi.

40. Iubeo etiam et] $R$ Otorgo et; nunquam] $R$ que non. 


\section{El fuero de Córdoba: edición crítica y traducción}

Pero acerca de las villas del obispo de Córdoba y las aldeas, y 37 de la iglesia de Santa María, mandamos como sigue: que la posta y facendera que, como acabamos de decir, deben hacer con los vecinos de Córdoba, no la realicen personalmente, sino por medio de un hombre del señor obispo ${ }^{21}$, quien deberá recaudarla y entregarla a los alcaldes de Córdoba; pues no queremos que los alcaldes ni los vecinos de Córdoba tengan potestad alguna ni competencia de apremio sobre los hombres del obispo y de la iglesia de Santa María.

2 Y con esta pecha que harán a los ciudadanos de Córdoba, queden libres y exentos de toda pecha y facendera del rey.

3 Si yo o un hijo mío o alguno de mi linaje quisiere obtener otra pecha u otra facendera de los hombres mencionados del señor obispo o de la iglesia de Santa María, no estén obligados a satisfacer pecha ni facendera alguna con los ciudadanos de Córdoba.

Decreto también y confirmo que ningún cordobés, hombre o mujer, 38 pueda dar ni vender su heredad a ninguna orden, salvo que quiera donarla o venderla a la iglesia de Santa María de Córdoba, por tratarse de la iglesia-sede de la ciudad. Pero de sus bienes muebles dé cuanto quisiere, según su fuero.

$2 \mathrm{Y}$ la orden que recibiere tal heredad por donación o compra, que la pierda.

$3 \mathrm{Y}$ quien la vendiere pierda el importe de la transacción, que deberá pasar a sus parientes más próximos.

El caballero de otra parte que tenga o tuviere heredad en Córdoba, 39 haga allí vecindad con sus vecinos; en caso contrario, piérdala y entréguela el rey a quien quisiere, con tal que por ella haga vecindad. Mando también y concedo que los peones vecinos de Córdoba y 40 de su término nunca paguen diezmo al rey.

21 Puede referirse al mampostero, encargado de recaudar y administrar diezmos, rentas, limosnas etc. 
41 Concedo etiam et mando quod nullus uicinus morator de Corduba nec de suo termino det portaticum ullum in Corduba nec in suo termino.

42 Similjter concedo quod nullus uicinus de Corduba nec de suo termino det portaticum ullum de aliqua uenatione $\left.\right|^{31}$ de monte nec de piscatione de riuis.

43 Concedo etiam statuendo quod omnis homo qui iusticiatus fuerit, sui heredes habeant bona sua, nisi forte iusticiatus fuerit quia occidit hominem super saluo, uel occidit hominem super tregua, uel nisi iusticiatus fuerit pro moneta falsa, uel quia occidit hominem securum, uel nisi fuerit falsarius uel hereticus.

2 Et quicumque iusticiatus fuerit pro istis causis supradictis, rex habeat bona sua.

44 Mando etiam et concedo $\left.\right|^{32}$ quod concilium Cordubense habeat sigillum cognitum et comune.

45 Mando etiam et concedo quod non habeant uexillum quod aguardent, nisi uexillum regis, ubj rex fuerit.

$2 E t$ pro ad suos apellitos et pro ad suos adiuntamentos et pro ad suas cabalcatas accipiant qualemcumque uexillum uoluerint et ponant illud in manu iudicis.

$3 E t$ habeat duodecim caballerias.

$4 E t$ iudex semper sit talis qui teneat arma de fustibus et de ferro et $\left.\right|^{33}$ loricam de caballo.

$5 E t$ sigillum ciuitatis et claues teneat semper iudex.

46 Jubeo etiam et concedo quod omnis miles de Corduba possit accipere stipendium de seniore, saluo iure et seruitio regis.

$2 E t$ si castellum aliquod ganauerit quicumque morator de Corduba, det illud regi.

41. etiam et] $R$ et.

42. Similiter] $R$ Otrossi les; det portaticum ullum] $R$ non de portadgo.

43. Concedo etiam statuendo] $R$ Otorgoles; bona sua] $R$ so auer; nisi forte] $R$ si non si; tregua] $L$ treuga; nisi iusticiatus fuerit] $R$ omite; 43.2. quicumque] $R$ aquel que; bona sua] $R$ so auer.

44. Mando etiam et concedo] $R$ Otorgo et mando; concilium Cordubense habeat] $R$ habeant; et comune] $R$ omite.

45. Mando etiam et concedo] $R$ Otorgo et mando; nisi uexillum] $R$ fuera a la; rex] $R$ el. 45.2. qualemcumque uexillum uoluerint] $R$ qual se quisieren. 45.4. talis] $R$ a tal. 45.5. teneat] $R$ tengalas; semper] $R$ omite.

46. Iubeo etiam et concedo] $R$ Otorgo et mando; possit] $R$ que pueda; aliquod] $R$ omite; quicumque] $R$ por si caballero o tod omme. 
Otorgo asimismo y ordeno que ningún vecino residente en Córdoba 41 o su término pague portazgo ${ }^{22}$ alguno en Córdoba ni en su término.

Igualmente concedo que ningún vecino de Córdoba y su término 42 satisfaga portazgo alguno por ninguna caza de monte ni pesca de ríos.

Concedo también y ordeno que los bienes de todo hombre ajusticiado pasen a sus herederos, a menos que fuere ajusticiado por matar a hombre sobre salvo ${ }^{23}$, o por haberlo matado durante una tregua, por falsificación de moneda, por matar a hombre seguro ${ }^{24}$, o por tratarse de un falsario o hereje.

$\mathrm{Y}$ todos los bienes de los ajusticiados por estas causas pasarán a poder del rey.

Ordeno también y doy que el concejo de Córdoba tenga sello conocido y común.

Mando además y concedo que, donde el rey estuviere, no tengan otra bandera que aguardar que el pendón real.

$2 \mathrm{Y}$ para sus apellidos ${ }^{25}$, para sus ayuntamientos ${ }^{26}$ y para sus cabalgadas ${ }^{27}$ adopten cualquier ${ }^{28}$ enseña y pónganla en mano del juez.

3 Y tenga éste doce caballerías.

$4 \mathrm{Y}$ el juez sea siempre hombre que posea armas de fuste y de hierro y loriga de caballo.

$5 \mathrm{Y}$ que el juez custodie siempre el sello y las llaves de la ciudad. Ordeno asimismo y concedo que todo caballero de Córdoba pueda 46 percibir soldada de un señor, una vez garantizado el derecho y servicio del rey.

22 Impuesto que gravaba la circulación de mercancías y las transacciones efectuadas en los mercados. El impuesto se pagaba en la "porta".

23 Estaba considerado entre los delitos más graves el matar a alguien que gozara de fianza o "fiaduría" de salvo, esto es, a quien antes se le hubiere asegurado que no habría de recibir daño..

24 Cf. nota precedente.

25 Llamamiento para una operación militar.

26 Juntas, reuniones.

27 Incursiones rápidas en campo enemigo a modo de razzias.

28 La expresión latina qualemcumque uexillum entraña un evidente error, al concertar el indefinido en masculino con el sustantivo neutro uexillum. 
47 Jubeo insuper et concedo quod non habeant litem nisi super rem sarracenicam.

48 Concedo etiam statuendo quod non puniatur unus pro alio: nec filius $\left.\right|^{34}$ pro patre nec pater pro filio, nec maritus pro uxore neque uxor pro marito; set quicumque malum fecerit ipse puniatur rebus propiis et persona.

49 Jubeo etiam et concedo quod armeros qui faciunt brisones de scutis et de sellis, et loricarij et alfayates et pellicarij non uadant ad tendas regis per premiam. Omnes alij ministeriales uadant ad tendas regis quas prius locent; quibus locatis, uadant ad tendas militum $\left.\right|^{35}$ quas eos rex dimisit in tenencia.

50 Concedo insuper et mando quod quicumque occiderit hominem, pro inimico exeat de uilla et non sit ante oculos consanguineorum ipsius. $2 E t$ iuramentum quod debuerit facere qui se habuerit saluare, faciat secundum forum Cordube.

3 Et quando debuerint eum recipere, recipiant eum per idem forum.

51 Concedo insuper et mando quod quicumque fregerit domum uicinj de Corduba morte moriatur. Et si non $\mid{ }^{36}$ potuerint ipsum comprehendere, amitat omnia bona sua et exeat pro inimico de uilla et de suo termino.

2 Et si frangendo domum hominem occiderit, moriatur pro eo.

3 Et si illum fractorem domus in frangendo domum interfecerint, qui eum interfecerit non sit inimjcus nec pectet homicidium pro eo. 4 Et si fractor domorum fugerit uel se absconderit in aliqua domo, dominus domus ubj fuerit suspectus quod iacet, teneatur dare domum $\left.\right|^{37}$ ad scrutinium iudicj et alcaldibus.

5 Et si noluerit eam dare ad scrutinium, teneatur pati penam quam debebat pati fractor domus si inuentus esset.

47. Iubeo insuper et concedo] $R$ Otorgo et mando; rem sarracenicam] $R$ auer morisco.

48. Concedo etiam statuendo] $R$ Otorgo et mando; ipse puniatur rebus propiis et persona] $R$ esse lo padesca et lo suyo.

49. Iubeo etiam et concedo] $R$ Otorgo et mando; non uadant] $R$ que non uayan; quas] $R$ et las tiendas del rey; locent] $R$ lueguen et; rex] $R$ omite.

50. insuper et] $R$ et; ipsius] $R$ omite. 50.2. faciat] $R$ que la faga; Cordube] $R$ de Cordoba mandare. 50.3. idem] $R$ esse mismo.

51. insuper et] $R$ et; morte moriatur] $R$ que muera por ello; comprehendere] $R$ prender; omnia bona sua] $R$ quanto houiere; suo] $R$ omite. 51.5. penam quam debebat] $R$ tal penna como deue. 
El fuero de Córdoba: edición crítica y traducción

2 Y si algún habitante de Córdoba conquistare un castillo, que se lo dé al rey.

Mando además y concedo que no mantengan contiendas sino con $\mathbf{4 7}$ los sarracenos.

Otorgo igualmente y dispongo que no sea castigado uno por otro: ni hijo por padre ni padre por hijo, ni marido por esposa ni ésta por su marido; sino que el mismo causante del delito sea castigado en sus propios bienes y persona.

Mando asimismo y concedo que los armeros que hacen brisones de escudos y sillas, los lorigueros, sastres y pelliqueros no estén obligados a acudir a las tiendas del rey; todos los demás menestrales vayan a las tiendas del rey que serán las primeras en asentarse $y$, una vez colocadas, acudan a las que los caballeros recibieron del rey en tenencia.

Concedo además y ordeno que todo el que matare a un hombre, 50 salga como enemigo de la villa y no permanezca a la vista de los consanguíneos de aquél.

$2 \mathrm{Y}$ el juramento que hubiere de hacer el que tenga que salvarse, hágalo por el Fuero de Córdoba.

$3 \mathrm{Y}$ cuando debieren tomárselo, tómenselo por el mismo Fuero. Concedo además y dispongo que todo el que violare el domicilio de un vecino de Córdoba, lo pague con la muerte. Y si no pudieren prenderle, pierda todos sus bienes y salga como enemigo de la villa y de su término.

2 Y si al violar el domicilio matare a alguien, muera por ello.

3 Si mataren al violador del domicilio in fraganti, quien lo matare no sea declarado enemigo ni sea reo de homicidio por ello.

$4 \mathrm{Y}$ si el violador del domicilio huyere o se escondiere en alguna casa, el dueño de la casa donde se sospeche que se hubiere escondido, estará obligado a dar su casa al juez y los alcaldes para que la registren.

5 Y si no accediere a entregarla para registro, cargará con la pena que debía padecer el violador de morada, de ser encontrado. 
52 Item statuo et concedo quod quicumque occiderit hominem securum, talem sucurum cum quo non habuit antea uerba turpia nec iurgiam nec contendam, nec in ora mortis nec ante, moriatur pro illo et amitat omnia bona sua et accipiat ea rex.

53 Item mando et concedo $\left.\right|^{38}$ quod archiepiscopus et episcopi et ordines et riqui homines et milites et clericj et omnes illj qui aliquit habuerint in Corduba, quod dent mampostarium per quem faciant directum et per quem recipiant directum.

54 Item statuo et mando quod Liber Iudicum, quem ego dabo Cordubensibus, translatetur in uulgare et uocetur Forum de Corduba cum omnibus supradjctis.

$2 \boldsymbol{E} t$ quod hec per secula cuncta sint pro foro et nullus sit au- $\left.\right|^{39}$ sus istud forum aliter apellare nisi forum de Corduba.

55 Item iubeo et mando quod omnis morator et populator in heredamentis que ego dedero in terminis de Corduba archiepiscopis et episcopis et ordinibus et riquis hominibus et militibus et clericis, quod ueniant ad iudicium et ad forum de Corduba.

56 Item mando et concedo quod caficum salis non ualeat in salinis magis quam unum aureum.

57 Iubeo etiam statuendo quod ${ }^{40}$ alcaldes non accipiant pro pena magis quam unum aureum ab illis qui non uenerint ante illos ad suam citationem; et diuidant illum aureum alcaldus et demandator.

2 Et querellosus de foris de uilla habeat directum usque ad tertium diem et non prolongent ej magis directum alcaldes.

3 Et si mobile debuerint uendere pro debito quod debeant homini

52. Item statuo et concedo quod] $R$ Et; hominem] $R$ a otro; iurgiam nec contendam] $R$ contencia nin baraja; omnia bona sua] $R$ quanto ha.

53. Item mando et concedo] $R$ Otorgo y mando; per quem] $R$ por ond.

54. Item statuo] $R$ Otorgo; quem ego dabo Cordubensibus] $R$ que les yo do; translatetur] $R$ que gelo mandaré transladar. 54.2. Et quod hec per secula cuncta sint pro foro] $R$ Et que lo (Liber Iudicum) ayan siempre por fuero; nullus sit ausus] $R$ nenguno non sea osado; istud forum] $R$ le.

55. Item iubeo] $R$ Otorgo; dedero] $R$ diere; terminis] $R$ termino; et clericis] $R$ omite.

56. Item mando et concedo] $R$ Otorgo et mando.

57. Iubeo etiam statuendo] $R$ Otorgo; ab illis qui non uenerint ante illos ad suam citationem] $R$ por non uenir ante ellos aquel que fuere lamado al pleyto; illum aureum] $R$ el marauedi. 57.2. directum] $R$ lo. 57.3 (En latín se da una versión diferente al texto romance, aunque de contenido similar) radicem] $R$ heredat. 
Igualmente establezco y concedo que quien matare a un hombre $\mathbf{5 2}$ seguro, de tal manera que no hubieren mediado antes ofensas verbales ni disputa ni contienda, ni en el momento de la muerte ni antes, muera por ello y pierda todos sus bienes, que pasarán al rey.

Asimismo, mando y concedo que el arzobispo y los obispos, las órdenes y ricoshombres, caballeros y clérigos y cuantos tuvieren algo en Córdoba, nombren un mampostero por medio del cual hagan y reciban derecho.

De igual modo, ordeno y mando que el «Liber Iudicum», que voy a dar a los cordobeses, sea traducido al romance y sea llamado Fuero de Córdoba con todo lo antedicho.

$2 \mathrm{Y}$ que todo esto permanezca por fuero hasta la consumación de los siglos y nadie se atreva a llamar este fuero de otra manera, sino Fuero de Córdoba.

Asimismo, dispongo y ordeno que todos los moradores y pobladores en las heredades que yo daré en término de Córdoba a los arzobispos y obispos, órdenes y ricoshombres, caballeros y clérigos, acudaì a la jurisdicción y fuero de Córdoba.

Otorgo además y concedo que el cahíz ${ }^{29}$ de sal no valga en las salinas más de un maravedí.

Mando también y dispongo que los alcaldes no sancionen con más de un maravedí a quienes no comparecieren ante ellos tras ser citados; y que se repartan el áureo el alcalde y el demandante. $2 \mathrm{Y}$ el querellante de fuera de la villa tenga derecho hasta el tercer día y no le prolonguen más su derecho los alcaldes.

$3 \mathrm{Y}^{30}$ si hubieren de vender bienes muebles para saldar la deuda a un forastero, véndanlos hasta el tercer día; y si bienes raíces, véndanlos hasta el día noveno.

29 Medida de capacidad equivalente en Castilla a unos 666 litros.

30 Este epígrafe se corresponde con el último de la versión romance, es decir, el 26.4 . 
$\mathrm{d} e$ foris de uilla, uendant usque ad tertium diem; et si radicem

$I^{41}$ debuerint uendere, uendant usque ad nouem dies.

58 Item statuo et mando quod quicumque hominem occederit pro quo debeat pectare omicidium, sit pena omicidij ducentj et sexaginta morabetinj.

$2 E t$ de istis morabetinis habeat rex sexaginta. Et de ducentis qui remanent habeat querellosus octuaginta. Et de alijs centum uigintj accipiat rex tertiam partem; et alios qui remanserint diuidant ${ }^{42}$ iudex et alcaldes et scribanus.

3 Et si non potuerit habere illos morabetinos ille qui homicidium debet pectare, sit captus in potestate concilij et iudicis et alcaldium; et tota illa pena, quam debitor debet habere et forum mandat, fiat ej usquequo det predictos morabetinos.

Et hec mee donationis, concessionis et confirmationis pagina rata et stabilis omnj tempore perseueret.

Si quis uero hanc cartam $\left.\right|^{43}$ infringere seu in aliquo diminuere presumpserit, iram Dej omnipotentis plenarie incurrat et regie parti mille aureos in capto persoluat et cum Juda, Dominj proditore, penas sufferat infernales.

Facta carta apud Toletum VIII ${ }^{\mathrm{a}}$ die Aprilis era $\mathrm{M}^{\mathrm{a}} \mathrm{CC}^{\mathrm{a}} \mathrm{LXX}^{\mathrm{a}}$ nona. Et ego, prenominatus rex Ferrandus, regnans in Castella et Toleto, Legione, Gallecia et Corduba, Badallocio et Baecia, hanc cartam quam fieri iussi, manu propria roboro et confirmo.

(Signo rodado):

+ SIGNVM | FERRANDI | REGIS CASTELLE | ET TOLETI | LEGIONIS | GALLECIE | ET | CORDUBE.

Didacus Lupi de Faro, alferiz dominj regis, confirmat.

Rodericus Gonçaluj, maiordomus curie regis, confirmat.

(Tras la roboración)

Rodericus, Toletane sedis archiepiscopus, Yspaniarum primas, confirmat.

Infans Alfonsus, frater dominj regis, confirmat.

Iohannes, Compostellane sedis archiepiscopus, confirmat.

(Canciller)

Iohannes, Burgensis episcopus, dominj regis cancellarius, confirmat.

58. Item statuo et mando quod] $R$ omite; pena omicidii] $R$ omezilio. 58.2. sexaginta] $R$ los sesanta morabedis; octuaginta] $R$ los ochaenta morabedis; aliis] $R$ los; qui remanserint] $R$ omite. 58.3. illos] $R$ los; sit captus in potestate concilii] $R$ sea preso en preson de concejo; predictos] $R$ los. 
También establezco y mando que quien matare a un hombre, por $\mathbf{5 8}$ lo que deba pagar multa de homicidio, abone la cantidad de doscientos sesenta maravedís.

2 De éstos el rey tomará sesenta; y de los doscientos restantes el demandante recibirá ochenta; y de los otros ciento veinte tome el rey la tercera parte y el resto distribúyanselos el juez, los alcaldes y el escribano.

3 En caso de que el reo de homicidio no pudiere aportar tal cantidad, permanezca preso en poder del concejo, del juez y los alcaldes, aplicándosele toda la pena que el deudor debe sufrir y el fuero manda hasta que entregue los maravedís antedichos.

$\mathrm{Y}^{31}$ esta carta de mi donación, concesión y confirmación persevere firme y estable en todo tiempo.

Por tanto, si alguien osare infringir esta carta o menguarla en algo, incurra plenamente en la ira de Dios omnipotente, pague al rey mil maravedís de multa y sufra las penas infernales con Judas, el traidor al Señor.

Hecha la carta en Toledo, el día 8 de Abril de 1241.

$\mathrm{Y}$ yo, el antedicho rey Fernando, reinando en Castilla y Toledo, León, Galicia y Córdoba, Badajoz y Baeza, que la mandé escribir, la rubrico y autentifico con mi propia mano.

(Signo rodado)

+ SELLO DE FERNANDO, REY DE CASTILLA Y TOLEDO, LEÓN, GALICIA Y CÓRDOBA.

Diego López de Haro, alférez del señor rey, confirma.

Rodrigo González, mayordomo de la curia real, confirma.

(Tras la roboración)

Rodrigo, arzobispo de la sede de Toledo, primado de las Españas, confirma.

El infante Alfonso, hermano del señor rey, confirma.

Juan, arzobispo de la sede de Compostela, confirma.

(Canciller)

Juan, obispo de Burgos y canciller real, confirma.

31 El texto romance carece de las fórmulas protocolarias finales, concluyendo con la data, 3 de Marzo de 1241. 
(Primera columna)

Tellius, Palentinus episcopus, confirmat; Bernaldus, Segobiensis episcopus, conf.; Gonçaluus, Conchensis episcopus, conf.; Ferrandus, Segontinus episcopus, conf.; Aznarius, Calagurritanus episcopus, conf.; Petrus, Oxomensis episcopus, conf.; Lupus, Cordubensis episcopus, conf.; Adam, Plazentinus episcopus, conf.; Dominicus, Beaciensis episcopus, conf.; Ecclesia Abulensis uacat.

(Segunda columna)

Garsias Ferrandj conf.; Alfonsus Lupi conf.; Alfonsus Tellij conf.; Egidius Malricj conf.; Rodericus Ferrandj conf.; Goncaluus Goncaluj conf.; Rodericus Rodericj conf.

(Tercera columna)

Martinus, Legionensis episcopus, conf.; Iohannes, Ouetensis episcopus, conf.; Petrus, Çamorensis episcopus, conf.; Martinus, Salamantinus episcopus, conf.; Nunius, Astoricensis episcopus, conf.; Micahel, Lucensis episcopus, conf.; Laurencius, Auriensis episcopus, conf.; Micahel, Ciuitatensis episcopus, conf.; Lucas, Tudensis episcopus, conf.; Sancius, Cauriensis episcopus, conf.

(Cuarta columna)

Rodericus Gomez conf.; Rodericus Ferrandj conf.; Ramirius Florez conf.; Rodericus Florez conf.; Petrus Poncij conf.; Ferrandus Iohannis conf.; Ordonius Aluari conf.; Sabastianus Guterrij conf.; Pelagius Arie conf.; Pelagius Petri conf.

Martinus Gonçaluj, maior merinus in Castella, confirmat.

Munio Ferrandj, maior merinus in Gallecia, confirmat.

Garsias Rodericj, maior merinus in Legione, confirmat.

(Linea inferior)

Iohannes Petri, Soriensis, iussu dominj regis scripsit. 


\section{(Primera columna)}

Tello, obispo de Palencia, confirma; Bernardo, obispo de Segovia, conf.; Gonzalo, obispo de Cuenca, conf.; Fernando, obispo de Sigüenza, conf.; Aznario, obispo de Calahorra, conf.; Pedro, obispo de Osma, conf.; Lope, obispo de Córdoba, conf.; Adam, obispo de Plasencia, conf.; Domingo, obispo de Baeza, conf.; La diócesis de Ávila está vacante.

(Segunda columna)

García Fernández conf.; Alfonso López conf.; Alfonso Téllez conf.; Egidio Manrique conf.; Rodrigo Fernández conf.; Gonzalo González conf.; Rodrigo Rodríguez conf.

(Tercera columna)

Martín, obispo de León, conf.; Juan, obispo de Oviedo, conf.; Pedro, obispo de Zamora, conf.; Martín, obispo de Salamanca, conf.; Nuño, obispo de Astorga, conf.; Miguel, obispo de Lugo, conf.; Lorenzo, obispo de Orense, conf.; Miguel, obispo de Ciudad Rodrigo, conf.; Lucas, obispo de Tuy, conf.; Sancho, obispo de Coria, conf.

(Cuarta columna)

Rodrigo Gómez conf.; Rodrigo Fernández conf.; Ramiro Flórez conf.; Rodrigo Flórez conf.; Pedro Ponce conf.; Fernando Yáñez conf.; Ordoño Álvarez conf;; Sebastián Gutiérrez conf. Pelayo Arias conf. Pelayo Pérez conf.

Martín González, merino mayor en Castilla, conf.

Nuño Fernández, merino mayor en Galicia, conf.

García Rodríguez, merino mayor en León, conf.

(Línea inferior)

Juan Pérez, soriano, por mandato del señor rey, la escribió. 


\section{A modo de conclusión}

No queremos concluir sin redactar unas reflexiones a la luz de los datos que nos proporciona el aparato crítico, que sólo pretenden ser una breve muestra del fruto que se puede obtener de él. Pero antes recordaremos que nos movemos en tres planos diferentes, coincidentes con los tres bloques de fuentes de nuestro fuero, ya identificados en la introducción, y que el aparato crítico de cada uno de ellos nos proporciona información con perfiles peculiares:

- En el bloque de rúbricas traducidas al latín desde la redacción romance (1-3 y 40-58) predominan los aspectos lingüísticos, en la medida en que el traductor, al poner el texto en latín, no sólo deja constancia de su valoración (interpretación) tanto léxico-semántica como gramatical de los términos y construcciones romances, sino que, al mismo tiempo, pone en evidencia el nivel y características del latín que se aprendía en las escuelas en aquella época.

- El aparato crítico del bloque tomado del fuero de los mozárabes es homologable a cualquier modelo tradicional y, por tanto, es el que se presta más a consideraciones sobre la historia e interrelación de los textos.

- Finalmente, en el de las rúbricas 34-39, la peculiaridad viene dada por el hecho de que se conservan los originales respectivos de donde pasaron a la confirmación de Fernando III de 1222, por lo que la concordancia entre $F$ y el original respectivo (or.) garantiza la lectura del original fernandino frente a posibles variantes de $L$.

\subsection{Observaciones al primer bloque:}

Aparte de particularidades concretas que, sin ser muy relevantes, merecerían tal vez más atención del filólogo, se acusan determinadas tendencias dignas de señalar. La primera de ellas, la traducción del artículo determinado por el adjetivo demostrativo (ille): illa en $1.3 \mathrm{y}$ 1.13 , ille en 1.11 , illi en 1.8 , illos en 1.8 y 58.3, illum en 57 , fenómeno explicable por una tendencia lingüística característica del latín medieval. A un fenómeno lingüístico similar se debe también el sobrepujamiento de la conjunción copulativa, traducida al latín por etiam et en 40, $41,44,45,46$ y 49, y por insuper et en 47, 50 y 51. Pero constatamos 


\section{El fuero de Córdoba: edición crítica y traducción}

al mismo tiempo otras traducciones, como la del adjetivo praedictus en lugar del artículo determinado (praedicta en 1.4 y 1.6 -dos ocurrencias- y praedictos en 58.3), que no admiten explicación lingüística alguna, sino que delatan una actitud relajada por parte del traductor.

Esta misma actitud se manifiesta palpablemente y con especial intensidad tanto en la copia (rúbricas 4-39) como en la traducción de los inicios de las rúbricas, con amplia muestra de variantes, según puede verse en el aparato crítico. Obsérvense, sólo a título de ejemplo, las diferentes formas de traducir al latín el inicio romance «otorgo et mando»: mando et concedo (44 y 45), iubeo etiam et concedo (46 y 49), iubeo insuper et concedo (47), concedo etiam statuendo (48), item mando et concedo (53 y 56), donde, más que una traducción literal, lo que parece pretenderse es justamente la uariatio, máxime cuando se recurre a estas fórmulas o similares incluso allí donde el texto romance carece de verbo introductor del mandato o donación, por ejemplo item statuo et concedo quod (52), e item statuo et mando quod (58), recurso ya utilizado en rúbricas precedentes, cuando copiaba textos latinos que tenía que adaptar: concedo itaque uobis ut (4), mando (8), item statuo (25), item iubeo et concedo quod (26, 29 y 33), iubeo statuendo (30), y dono insuper et (35) etc.

\subsection{Segundo bloque (rúbricas 4-33):}

Es, sin duda, el apartado que más nos interesa para la historia de los textos, por lo que centramos en él nuestras observaciones. Pero antes de sumergirnos en su estudio, debemos recordar que el trasvase de los textos forales toledanos (el $52 \%$ de la parte dispositiva de nuestro fuero), redactados en tercera persona y destinados a los moradores de Toledo, exige variantes producidas por la necesaria adaptación a las nuevas circunstancias (ahora es el rey quien otorga en primera persona y los beneficiarios son la ciudad de Córdoba y sus vecinos); por esta razón, en los cómputos de variantes a los que vamos a recurrir, no incluiremos nunca las producidas por tal exigencia (ille / ego, iussit / iubeo, Toletum / Corduba etc.).

Pues bien, para ayudar a la elaboración de conclusiones acerca de la historia de los textos, basadas en algo más fiable que la pura apreciación, facilitaremos unos cómputos sobre las variantes pertinentes, sin entrar a considerar la entidad de las mismas. Pero, recordamos, en este apartado no abarcamos todo el texto procedente de los fueros 
toledanos, sino sólo el tomado del fuero de los mozárabes (rúbricas 4-33), lo que supone sólo el $36 \%$ del total del fuero.

Los textos de este bloque abarcan un total de 950 palabras en las que se registran 139 variantes computables (utilizando, obviamente, como texto base el de nuestro fuero), cuyo estudio nos va a permitir dibujar los perfiles de cada uno de los cuatro documentos utilizados.

En primer lugar, en 50 de esas 139 variantes (el 36\%) $L$ se opone a la lectura concordante de los otros tres, $T, A, F$, por lo que no cabe duda alguna de que la lectura de éstos coincide con la del original perdido de la confirmación de Fernando III o, dicho de otra manera, que dichas variantes son responsabilidad de nuestro copista. Aunque el número total de variantes exclusivas de nuestro texto (incluidas también aquellas en que los otros tres no coinciden entre sí) se eleva a 77 (cifra algo superior al 54\%) ${ }^{1}$.

Pero si comparamos el texto de $L$ con cada uno de los demás, individualmente, obtendremos los resultados siguientes: el mayor número de divergencias se da entre $L$ y $A$, con un total de 126 variantes entre ellos, (esto es, casi el $91 \%$ de las variantes), lo que -dicho desde otra perspectiva- significa que sólo en 13 ocasiones $L$ y $A$ se encuentran en el mismo frente en el aparato crítico. Le sigue $T$, con 101 divergencias entre ellos (casi el 73\%), esto es, -desde la perspectiva opuesta-, en 38 ocasiones se alinea $L$ con $T$ cuando existen variantes. Finalmente, $L$ se aparta en 89 ocasiones de las lecturas de $F$ (el 64\%), o, dicho en positivo, en 50 ocasiones $L$ y $F$ comparten variante. Este mayor índice de coincidencias entre $L$ y $F$, aparte de esperado (ambos descienden del mismo original), constituye un dato de primera magnitud en orden a la fijación del texto fernandino de la confirmación de 1222: sus variantes respecto de $T$ y $A$ reproducen puntualmente variantes ya presentes en dicha confirmación fernandina, pues $L$ y $F$ son independientes entre sí.

Si centramos ahora la atención en los tres pergaminos toledanos, podemos deducir que, a la vista de concordancias y divergencias, $F$ no debió compartir modelo con $A$, como ya adelantábamos en la introducción contra lo afirmado por García-Gallo, sino, en todo caso, con $T$ en cuya línea de transmisión se alinea: en efecto, $F$ y $A$ comparten variante sólo en 60 ocasiones (43\%), y difieren en 79 (57\%); mientras que $T$ y $F$ comparten 103 (el $74 \%$ de las variantes) y difieren en sólo 36 (el 26\%), siendo los dos textos que presentan mayor proximidad de los cuatro aquí relacionados. A esto hay que añadir también la gran distancia entre $T$ y $A$, entre los que predominan también las divergencias, 72, (esto es, el 52\%), frente a las concordancias, 67, (es decir, el $48 \%$ ). 


\section{El fuero de Córdoba: edición crítica y traducción}

Este mismo alejamiento de $A$ frente a los otros dos toledanos se aprecia también contabilizando las variantes exclusivas de cada uno de ellos: $F$ presenta sólo 13 y $T 16$, mientras que en $A$ se elevan a 55 , cifra muy elevada tratándose de una copia en la que se pretende reproducir literalmente el modelo. Pero la misma conclusión obtenemos si analizamos en el seno de las variantes cómo se distribuyen los apoyos. Así, de las 139 variantes, $T$ y $F$ concuerdan en 103 ocasiones, mientras que las concordancias entre $T$ y $A$ se reducen a 67 y entre $A$ y $F$ descienden a 60 .

Parece, por tanto, obligado adscribir $F$ a la línea de $T$, aunque el copista de $F$ debió tener a la vista también una copia de la familia más próxima a $A$, como lo acreditan varias lecturas concordantes: ergo de $A$ y $F$ en 23 (única aparición de la partícula en estos textos) frente a la lectura uero, más usual, de $T$ y $L$; en 31 succurrat Toletum deffendere, asimismo de $A$ y $F$, frente a succurrat Toleto et defendat de $T$, en 27 mala si fuerit aut bona, de $A, F$ y $L$, frente a siue bona siue mala de $T$ etc. También se puede apreciar en alguna curiosa vacilación de $F$, por ejemplo, en un texto no trasvasado al fuero de Córdoba, inmediatamente anterior a nuestra rúbrica 15 , ante la disyuntiva de lecturas de $T$ sine ullo timore, y la de $A$ sine ulla prohibitione, $F$ vacila y anota sine ulla timore.

A pesar de lo dicho y de ser $A$ el texto más alejado no sólo del nuestro sino también de los otros dos de la familia toledana, nos sirve para corregir tanto a $T$ como a $F$; pero, asimismo, determinadas concordancias con $L$, frente a los otros dos, demuestran que el redactor del cordobés, además de su modelo natural, el original de la confirmación fernandina de 1222, tuvo delante también otro pergamino de la familia de $A$. Tal ocurre, por ejemplo, en 10, aliqua arma, frente a aliquas armas de $T$ y $F$; en 14 aliquibus, frente a quibusdam de $T$ y $F$; en 17 propter, frente a per de $T$ y $F$; en 24 patiatur, frente a pateat de $T$ y $F$ etc. Variantes todas ellas que, aunque no son numéricamente importantes, sí son suficientemente significativas.

\subsection{Tercer bloque (rúbricas 34-39)}

Dada la naturaleza de los tres documentos que hemos utilizado en este bloque, la concordancia de dos de ellos garantiza la lectura del texto de la confirmación fernandina, de donde fueron copiados $F$ y $L^{2}$. En efecto, teniendo como testigo el original de Alfonso VIII (or.), de una parte, cualquiera de ellos que coincida con el testigo corrige 
al otro y, de otra, la concordancia de ellos dos garantiza la coincidencia de ambos con su modelo. Pues bien, en estas seis rúbricas contabilizamos 39 variantes pertinentes: en 16 de ellas (el $41 \%$ ) concuerdan $F$ y $L$ frente a los textos originales respectivos de Alfonso VIII; mientras que la concordancia entre $F$ y or. se da en 17 ocasiones (el 43\%), y la de $L$ y or. sólo en 3 (el $8 \%$ ); por último, también en 3 ocasiones ninguno de los tres coincide, únicos pasajes, por tanto, en que no podemos garantizar el texto fernandino de la confirmación.

Como puede apreciarse, el fuero cordobés guarda mayor fidelidad al modelo en este bloque ${ }^{3}$ que en el anterior, teniendo un comportamiento muy similar a $F$. Pero aún así, a la vista de los datos proporcionados especialmente en el aparato crítico del bloque segundo, parece imponerse la opinión de que no se explica el gran volumen de variantes de nuestro texto si no aceptamos algo singular en él: los otros tres textos fueron copiados para ser sobrecartados, es decir, el copista se siente obligado a reproducir fielmente el modelo ${ }^{4}$; por el contrario, en el fuero de Córdoba el copista actúa con mucha más libertad, pues no se trata de copiar para confirmar exactamente los derechos ya otorgados con anterioridad, sino de traducir (rúbricas tomadas del romance) y adaptar (las de Toledo) con una redacción que no precisa necesariamente de la fidelidad absoluta, algo imposible por su propia naturaleza, para el otorgamiento de unos fueros nuevos a una ciudad reconquistada, sin tradición foral alguna. En definitiva, se trataría del mismo fenómeno que se repite después, cuando se toma como fuente el texto cordobés para otorgar los fueros a Carmona sin exigir absoluta fidelidad al texto, hasta el punto que, al menos a veces, más que de infidelidad de la copia, cabe hablar de una adaptación bastante ajustada al modelo, frente a la traducción literal que se hace, por ejemplo, para Écija, en la que prevalece la fidelidad al original.

\section{Notas de 1. Introducción}

* Este trabajo ha sido realizado dentro del marco del Proyecto de Investigación PB97-0462 de la DGES.

1 Mellado Rodríguez, J., 1990, Los textos del fuero de Córdoba y la regulación de los oficios municipales, Córdoba, Real Academia de Ciencias, Bellas Letras y Nobles Artes de Córdoba. Constituyó nuestro discurso de ingreso como miembro de número en dicha corporación, por lo que apareció también (con pequeñas variantes) en el Boletín de la entidad, BRAC 118, pp. 9-74. También en 1991 redactamos unas breves páginas para el II Congreso de Historia de Andalucía, con motivo de su 750 aniversario, 


\section{El fuero de Córdoba: edición crítica y traducción}

Mellado Rodríguez, J., 1994, "El fuero de Córdoba en su 750 aniversario", Actas del II Congreso de Historia de Andalucía. Andalucía Medieval, Córdoba, 1994, I pp. 217-223.

2 Rivera y Romero, V., 1881, La Carta de Fueros concedida a la Ciudad de Córdoba por el Rey D. Fernando III, Córdoba.

3 González, J., 1986, Reinado y Diplomas de Fernando III. Córdoba, vol. III, pp. 219-225. No debió ver los documentos originales, pues no sólo repite los mismos errores de Rivera y Romero, sino que se añaden otros nuevos.

4 García-Gallo, A., 1975, "Los fueros de Toledo", A.H.D.E. 45, pp. 341-488.

5 Cf. infra la distribución del texto.

5 Cf. infra la distribución del texto.

6 Hay que tener en cuenta un hecho trascendental: aún seguimos preguntándonos por las causas que indujeron al rey a cambiar, de manera tan tajante, su línea de actuación en el otorgamiento de fueros; son muchas las dudas que aún nos asaltan y enorme la trascendencia y significado que para la Historia del Derecho tiene el fuero de Córdoba por la brusca ruptura que supuso en la línea de expansión del Forum Conche a favor del de Toledo y la tradición jurídica de más rancio abolengo, el Fuero Juzgo. Desde luego, ninguna otra plaza anteriormente conquistada reunía tantos títulos como Córdoba, la antigua capital del califato, para merecer un tratamiento tan singular. No queremos decir con esto que los textos del fuero cordobés fueran redactados ex nouo para los cordobeses - salvo la rúbrica primera, cuyas deficiencias sólo pueden explicarse por la premura e improvisación-, pero seguimos creyendo, como afirmábamos en 1990, que la redacción de las rúbricas del romance «induce a considerarlas fruto de una selección laboriosa, pero rápida, realizada a modo de síntesis sobre una amplia base de textos. Los preceptos aparecen redactados de forma breve y concisa, presuponiendo frecuentemente una extensa materia jurídica. Se trata, sin duda, de rellenos, de añadidos para facilitar el acoplamiento y la adaptación de los privilegios otorgados a Toledo y de un código ya anticuado, el Fuero Juzgo, a las nuevas circunstancias de una ciudad recién conquistada y fronteriza, junto con el otorgamiento de un trato de favor a los cordobeses" (p. 17). Lo lógico es que esta selección se hiciera entre los preceptos ya existentes y en vigor en otros concejos, incluso quizá, en algún caso, a petición de los propios repobladores, habituados a tales normas en sus concejos de origen; queda por saber si se hizo tal selección sin pensar en los destinatarios concretos, como parece sugerir A. M. Barrero en un excelente trabajo (Barrero García, A. M., 1997, "El fuero de Carmona", Archivo Hispalense 80 , pp. 387-413), quien, en virtud de determinadas variantes, defiende, como más probable, la dependencia de ambos textos cordobeses y el de Carmona de un modelo común más o menos inmediato (p. 401, n. 45); pero cabe otra posibilidad, que particularmente nos parece más plausible: que se hiciera una selección pensando y a petición de los moradores de Córdoba, el original que conservamos, y que tal fuero sirviera posteriormente de modelo a seguir, fielmente en unos casos (p. e., Écija, con ligeras variantes, las propias de una copia), y en otros se hiciera una copia-adaptación un tanto libre, en la que se habría buscado más el contenido que la forma (p. e., Carmona).

7 González, J., 1980, Reinado..., vol. I, p. 416.

8 Es precisamente en esta data donde aparece por primera vez, en lo que hasta ahora sabemos, la fórmula "reg[e] expr[imente]" propia de los documentos fernandinos y no, como se ha dicho, a partir de 1246 (cf. González, J., 1980, Reinado..., vol. I, p. 256-257, de donde lo toma A. M. Barrero, o.c., p. 395).

9 El original se conserva en el archivo municipal, Secc. 1, serie 1, n. 2. De las diferentes ediciones anteriores a la nuestra (1990: 35-39), la mejor, sin duda, es la 
realizada por Carmen Crespo y publicada en 1972, Privilegios Reales y Viejos Documentos. IX Córdoba, Madrid, n. I. Ya hemos llamado la atención (1994) sobre el hecho de que determinadas peculiaridades del documento, (p. e., presencia de plica), podrían inducir al estudioso a pensar que gozó de cierta validez, pero parece evidente que, al menos desde que se firma el texto latino, existe la convicción de que es éste el auténtico y único fuero de Córdoba. Prueba de ello es que cuando se otorga este fuero a otras ciudades, por ejemplo a Écija, en 1266, se traduce literalmente el texto latino completo, a pesar de que habría sido más cómodo copiar simplemente el romance. Lo mismo cabe decir de las tres rúbricas del romance (11, 12 y 19) que, al no ser recogidas por el latino, no pasan a ningún otro posterior (cf. edición del fuero astigitano en Sanz Fuentes, $\mathrm{M}^{\mathrm{a}}$ J., 1978, "Aportación al estudio de la Cancillería de Alfonso X" GADES 1, pp. 183-208.

10 El original, en pergamino, se conserva en el Archivo Municipal de Córdoba, Sección 1, serie $1, \mathrm{n}^{\circ} 1$. También se conserva una copia de h. 1318 en el Archivo de la Catedral de Córdoba, Libro de las Tablas, fols. 84r-86v, (Nieto Cumplido, M., 1979, Corpus Mediaevale Cordubense I, Córdoba, $\mathrm{n}^{\circ}$ 237).

11 A pesar de otras opiniones (cf. nota 6). Lo que sí se aprecia es una actitud un tanto contradictoria en el traductor-copista del latino, pues, de una parte, se da excesiva dependencia, a veces, de la construcción latina respecto de la romance (especialmente en determinadas correlaciones de tiempos en verbos subordinados); pero, de otra, se permite ciertas licencias innecesarias, como puede constatarse en el aparato crítico, a lo que hay que añadir otro dato, ya aludido en nota 9 , que no casa bien con la existencia de ese hipotético modelo común que sugiere A. M. Barrero: la presencia de tres rúbricas en el romance $(11,12$ y 19) que no son recogidas en las redacciones posteriores (latino cordobés, Écija, Carmona etc.).

12 Nos referimos, una vez más, a las rúbricas 11, 12 y 19 del romance, que el latino ignora.

13 Como se podrá apreciar infra en la edición crítica.

14 A pesar de que el número de rúbricas es sensiblemente mayor que el del texto romance, la extensión de ambos textos es muy similar (48\% procedente del romance y $52 \%$ procedente de Toledo).

15 García-Gallo, A., 1975, pp. 386-388. Edición de la confirmación en Manuel y Rodríguez, M. de, 1800, Memorias para la vida del Santo Rey Don Fernando III, Madrid, pp. 313-317.

16 La data "Facta carta decimo sexto kalendas decembris era MCLVI", por un lapsus del redactor o copista, no debe referirse al cómputo por la era hispánica (como creemos haber demostrado en Mellado, J., 1990, o. c., p. 13, n. 15), esto es, el 1118, -lo que supondría, aparte de las incongruencias allí expuestas, el que Alfonso VII habría otorgado los fueros antes incluso de ser rey plenamente legítimo, meta que no consigue hasta 1126-, sino al de la Era Natiuitatis Domini Nostri que va a comenzar a imponerse poco después de esta fecha y, por tanto, al año 1156. Obsérvese que esta falta de atención viene avalada por hechos como la presencia de la frase "Bernaldus Dei gratia Toletane sedis archiepiscopus", al final, sin ir acompañada del esperado "confirmat" ni de otras confirmaciones: el copista encargado de hacer la recopilación, distraído, al concluir con uno de los privilegios refundidos, habría comenzado a copiar también, indebidamente, la relación de confirmantes de dicho privilegio, interrumpiéndola al percatarse de su error. Por lo demás, como ya se ha dicho, no se incluyen en el fuero cordobés todos los privilegios del fuero de los mozárabes, sino que se omiten algunos: entre las rúbricas 13-14 se omiten dos; entre la 14-15 uno; entre 


\section{El fuero de Córdoba: edición crítica y traducción}

21-22 uno; entre 24-25 uno y, finalmente, se omiten dos consecutivos tras la rúbrica 33.

17 García-Gallo, A., o. c., p. 486 (Apéndice 13, II); González, J., Alfonso VIII..., II, 392, p. 679 .

18 García-Gallo, A., o. c., p. 486 (Apénd. 13, III); González, J., Alf., III, 731, p. 285-286.

19 García-Gallo, A., o. c., p. 487 (Apénd. 13, V, 1); González, J., Alf., III, 793, p. 392 .

20 García-Gallo, A., o. c., p. 488 (Apénd. 13, VI, 1); González J., Alf., III, 792, p. 390 .

21 Cf. notas 9 y 10.

22 Por ejemplo, en 1.11, el texto latino traduce el sintagma el escriuano de $R$ por ille scriptor, algo importante para el filólogo, al constatar que, para el traductor, el demostrativo ille no tiene más valor que un simple artículo (aunque este fenómeno no se pueda considerar novedoso en latín medieval).

23 García-Gallo padece un doble error a este respecto: el primero, por creer que no se conserva el original; el segundo, al fechar esta confirmación el 2 de Marzo de 1252 (o. c., p. 386), tomando dicha fecha de la asignada erróneamente en la confirmación hecha por Alfonso XI el 18-3-1333, sin percatarse del error cometido por el redactor de este documento (cf. Izquierdo Benito, R., 1990, Privilegios reales otorgados a Toledo durante la Edad Media (1101-1494), Toledo, p. 37, n. 40). Pero el original se conserva en el Archivo Municipal de Toledo, Cajón 10, leg. 3, núm 6, donde aparece con absoluta nitidez la fecha de 2-3-1254. (Quiero aprovechar la oportunidad para dejar constancia de mi gratitud a dos archiveros, $D^{a}$ Ana A. Verdú Peral y D. Mariano García Ruipérez, de los Archivos Municipales de Córdoba y Toledo respectivamente, por su extraordinaria diligencia y generosidad).

24 Todas estas noticias, salvo observación en contra, están tomadas de García-Gallo, A., o. c., "Estudio crítico de los textos", pp. 344-388.

25 Se conserva en el Archivo Municipal de Toledo, Cajón 10, legajo 3, n ${ }^{\circ} 5$.

26 Muñoz Romero, T., Colección de Fueros Municipales y Cartas Pueblas, Madrid, 1847, pp. 365-369.

27 García-Gallo, A., o. c., p. 352.

28 Archivo Municipal de Toledo, Cajón 10, legajo 3, $\mathrm{n}^{\circ} 4$.

29 Cf. citas ya consignadas en notas 17-20.

30 Cf. nota 10. La pérdida afecta, en concreto, al texto comprendido entre illos ceciderint (rúbrica 11) e ire uoluerit (rúbrica 13).

\section{Notas de 3. A modo de conclusión}

$1 \mathrm{Y}$, curiosamente, sólo en cuatro ocasiones cada pergamino ofrece una lectura diferente a los otros tres (cf. aparato crítico de 12, 17, 26 y 27.2).

2 Objetivo importante, como valor añadido, y para el que nunca se ha utilizado, que sepamos, el texto de nuestro fuero.

3 Que, aunque está integrado por sólo seis rúbricas frente a las 30 del bloque segundo, alcanza casi la mitad de la extensión de éste (exactamente el 45\%).

4 De ahí que sea más llamativo el gran número de discrepancias de $A$. 